\title{
3D isotropic tactile microprobe based on a silicon parallelogram kinematic: from concept to fabrication
}

\author{
David Metz and Andreas Dietzel
}

\begin{abstract}
This work reports on a unique tactile microprobe based on a parallelogram kinematic made from monocrystalline silicon. This kinematic, made out of an orthogonal cascade assembly of three identical parallelograms, provides an isotropic behavior to the microprobe. Each parallelogram deflects in only one direction thanks to thin elastic silicon membrane hinges and their displacements are recognized using piezoresistors integrated into these hinges. Wide deflection ranges, isotropic behavior and low mechanical stiffness of the new microprobe, as predicted by simulations, could be verified in experiments. The fabrication, the assembly and the contacting of the first microprobe prototype was optimized to allow very compact integration into a $\varnothing 11 \mathrm{~mm}$ housing. This make it suitable for metrology research laboratories as well as industries equipped with conventional coordinate measurement machines and even for a variety of other 3D force/displacement measurements.
\end{abstract}

Index Terms - 3D microprobe, isotropy, silicon-parallelogram, piezoresistor, tactile measurement, coordinate measurement machine (CMM)

\section{INTRODUCTION}

Recently, we reported on a radically new microprobe design based on silicon parallelograms [1], which in essence are miniaturized versions of classical double bending beam load cells [2-4]. The miniaturization was facilitated by lithographic structuring and wafer level bonding of monocrystalline silicon. Here, we not only present the novel concept but also an improved realization including 3D microassembly. Further, we report on the progress for integrating the microprobe into a coordinate measurement machine (CMM).

Tactile probing systems enable the measurement of structures, which are hidden and/or optically not accessible, with a high accuracy and low uncertainty. Commonly, they are the sensing devices of a CMM, employed for dimensional measurements, together with a positioning system (typically: three axis). They get into contact with the to be measured workpiece via a probing element (e.g. a probing ball on a stylus) [5]. During the measurement, the position of the probing element is recorded und used to determine the workpiece geometry. A large number of microprobing systems or microprobes, based on different

Date of submission: 30.09 .2018

This work was supported the Deutsche Forschungsgemeinschaft, DFG, project number DI 1934/5-1.

D. Metz Author is with the Institute of Microtechnology, Technische Universität Braunschweig, Braunschweig, DE-38124 GERMANY (e-mail: d.metz@tu-bs.de). physical sensing principles, has been developed and optimized to respond the growing challenges of measuring microgeometries [6]. The glass fiber microprobe made by Werth GmbH, Germany, based on a development of the Physikalisch-Technische Bundesanstalt (PTB), combines tactile probing with the optical evaluation of the probing ball deflections. An ultra-small probing stylus made from a glass fiber with a probing ball diameter down to $20 \mu \mathrm{m}$ is used for $2 \mathrm{D}$ and 3D measurements with ultra-small probing forces down to $20 \mu \mathrm{N}$ [7-9].Through an optimized leaf spring, an anisotropy of 1.4 could be achieved [10]. At the UK's National Physical Laboratory (NPL), a three-legged microprobe has been made out of three beryllium-copper flexures, assuring the movability of a stylus placed in its center and the isotropic mechanical behavior of the system with a small stiffness of $10 \mathrm{~N} \cdot \mathrm{m}^{-1}$ over a working range of $\pm 20 \mu \mathrm{m}$. This sensor, (commercially available through IBS Precision Engineering, The Netherlands) provides a resolution of $3 \mathrm{~nm}$ using three capacitance sensors [11-14]. Another three-legged microprobe has been developed at Eindhoven University of Technology TUE (commercially available through XPRESS Precision Engineering B.V., The Netherlands) based on a anisotropic silicon suspension combined with piezoresistive sensors. It provides a repeatability of $4 \mathrm{~nm}$ and probing forces down to $0.01 \mathrm{mN}$ over a measuring range of $10 \mu \mathrm{m}$ [15-17]. A silicon-membranebased microprobe has been developed at the Technische Universität Braunschweig (TUBS) in cooperation with the PTB [18-26]. Depending on the probing direction, this microprobe with a stiffness of $1-20 \mathrm{mN} \cdot \mu \mathrm{m}^{-1}$ provides a resolution of 3$5 \mathrm{~nm}$ and a repeatability of 10-20 nm for a measuring range of $\pm 100-50 \mu \mathrm{m}[18,22]$. Also, vibrating microprobes have been developed for noncontact probing [27-31].

The challenges of measuring microstructures with such sensors are still high and the application of microprobes is still reserved to specific, very accurate and expensive micro-coordinate measuring machines $(\mu \mathrm{CMM})$. The aim of ongoing research, in cooperation with the PTB, is to allow the measurement of the smallest structures with a high accuracy, even on more widely available conventional CMMs by the integration of a microprobes [22-24]. Typical measurements of microgeometries, which require tip diameters smaller than

A. Dietzel. Author is with the Institute of Microtechnology, Technische Universität Braunschweig, Braunschweig, DE-38124 GERMANY (e-mail: a.dietzel@tu-bs.de). 
below $300 \mu \mathrm{m}$, are not possible on conventional CMMs. This limitation is imposed by the difficulty of using such small stylus and not by the lack of positioning accuracy of conventional CMMs. Microprobes presented above are known for small deflection ranges (between 10-100 $\mu \mathrm{m}$ ). This constraint made their integration and use in non-specialized set-ups or commercial CMMs difficult because the risk of damage is too high. A high mechanical anisotropy of some microprobes ,resulting from their membrane-based construction (e.a. silicon membrane) [15, 22], leads to high measurement uncertainties for inclined surfaces because of a slipping probing element. Some work has been dedicated to obtaining isotropic mechanics, which could not be achieved without increasing the stiffness and further reducing the maximum deflections of the system $[16,25,26]$. This is not desirable in micro measurements with very small and fragile tips, and makes integration even more difficult.

In conventional CMM, 3D probing systems are made of three stacked metal spring parallelograms (first proposed by Zeiss in 1973 ) providing a high resolution over a large deflection range $\pm 1 \mathrm{~mm}$ [5]. The Swiss Federal Institute of Metrology (METAS) has developed a microprobe with such structure machined from a single aluminum block. This construction provides a perfect mechanical isotropy with a stiffness lower than $20 \mathrm{~N} \cdot \mathrm{m}^{-1}$ and a large measurement range of up to $\pm 200 \mu \mathrm{m}$. In combination with an ultraprecision CMM, scanning repeatability of less than $10 \mathrm{~nm}$ could be obtained [32, 33]. On the downside, this precision engineering construction is much bulkier and heavier than typical microfabricated microprobes.

The new 3D microprobing system (3DSP), presented in this work, is composed of three tiny stacked silicon parallelograms (SPs) (Fig. 1a), which allow the system to deflect into the three orthogonal axes $X, Y$, and $Z$. This novel construction combines the advantage of an isotropic kinematic providing a large measuring range with those of advanced miniaturization and of silicon as a construction material. The working principles of the SPs is identical to the classical force transducers or double bending beam load cells. Their rigid coupling enforces a vertical shift of the load application point and an S-shaped deformation of both beams, which generates positive and negative stress zones. To measure this deformation/load, metallic strain gauges are placed at these zones (hinges). Double bending beam load cells are typically machined out of a metallic material and are commercially available (with ISO standard) but are also further investigated [2-4, 34-39]. The SPs used in this work are silicon-based miniaturized load cells with elastic hinges made of thin silicon membranes. To sense the deflections, piezoresistors are integrated into the membranes at positions, where mechanical stresses $(\sigma+, \sigma-)$ are concentrated (Fig. 1b). Monocrystalline silicon is a perfect material for microelectromechanical systems (MEMS) [40, 41], because of excellent mechanical properties not suffering from degradation [42] and temperature independent elasticity [4345]. In addition, doped silicon has the advantage of strong piezoresistivity (about 100 time higher than for the metallic materials), which can be used for sensing. Through a wafer level processing of the small SPs, a high integration density and high manufacturing accuracy can be provided at low fabrication costs.

In this work, the development and test of a prototype 3DSP suited for research but also for industrial use is presented. In a first step, mechanical simulations of a single SP were performed. Then, the microfabrication of the SP was developed on the wafer level to enable cost effective fabrication at larger quantities. Finally, the obtained first prototypes of SPs and of microassembled 3DSP were experimentally characterized to obtain a proof of concept. In the second step, a more compact assembly, and integration concept of the 3DSP was developed. The obtained new SPs and the 3DSP were experimentally characterized with an advanced setup to assess industrial suitability.

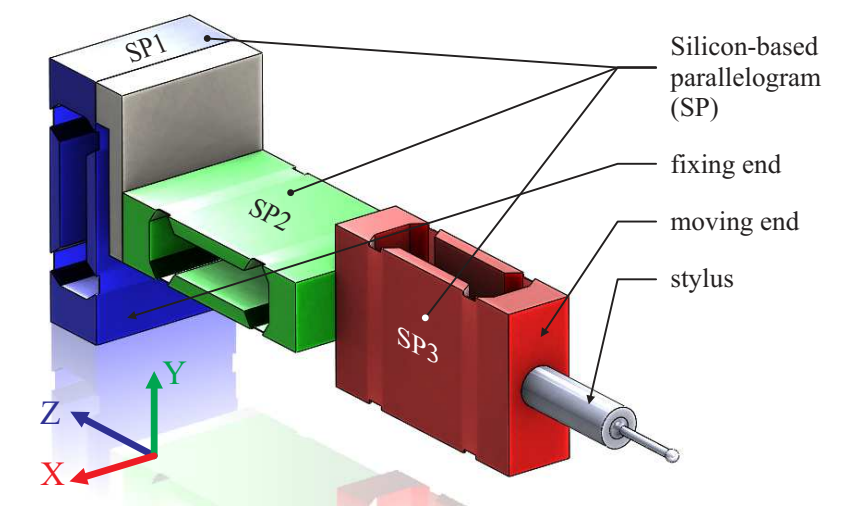

a.

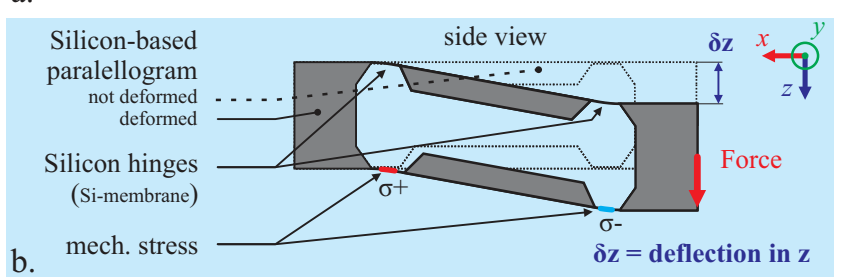

Fig. 1. a. Schematic of the 3DSP microprobe with stylus, and $b$. illustration of a SP deflected in its soft axis (z) direction. ${ }^{l}$

\section{PROOF OF ISOTROPIC 3D MICROPROBE CONCEPT}

The microprobe design supported by simulations, the microfabrication and the assembly process, as well as the characterization of a single SP was carried out before the first prototype of 3DSP could be tested.

\section{A. Simulation and dimensioning of the silicon based parallelogram $(S P)$ \\ 1) Conception and dimension of the $S P$}

The single SP was composed of three silicon parts: the front and rear springs and a spacer (Fig. 2a). As a result of commonly used (100) orientated silicon wafers and their typical dimensions, the front and the rear parts were taken as $360 \mu \mathrm{m}$ thick and the spacer in between as $1 \mathrm{~mm}$ thick, which resulted in a total SP thickness of $1.72 \mathrm{~mm}$. The parallelogram structure (with a length $l_{0}=4 \mathrm{~mm}$ ) was assured by two elastic hinges

${ }^{1}$ Please note the case of both carthesian systems:

upper case for the $3 \mathrm{DSP}(X, Y$, and $Z)$ and lower case for the $\operatorname{SP}(x, y$, and $z)$ 
made of a thin silicon membrane placed on both rear and front part. On the front, piezoresistors (R1, R2, R3, and R4) were placed within the membrane area, in longitudinal or transversal orientation, for the detection of the deflections, and were wired to form a Wheatstone bridge (Fig. 2b). This bridge excited by a voltage $\mathrm{U}$ (applied between pad/nodes $\mathrm{U}+$ and $\mathrm{U}-$ ) delivers a signal M (measured btw. pad/nodes $\mathrm{M}+$ and $\mathrm{M}-$ ) dependent on the deflection. The external dimensions $\mathrm{w} \times \mathrm{l} \times \mathrm{t}$ : $4 \mathrm{~mm} \times 6.5 \mathrm{~mm}$ $\times 1.72 \mathrm{~mm}$ of the SP were chosen by practical aspects of handling, contacting, and mounting. The fabricated SPs were glued to small printed circuit boards (PCBs) and contacted by manual soldering (Fig. 2c) for mechanical and electrical characterization (D.2)).

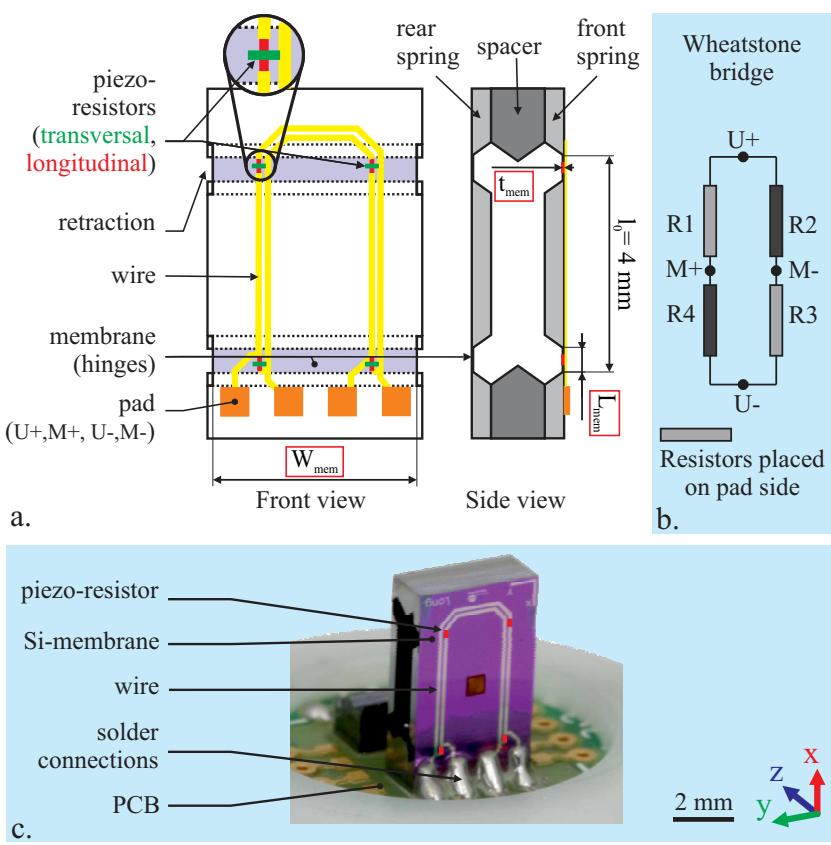

Fig. 2. a. Schematic of the top and side view of the SP with four wired piezoresistors. The geometric parameters varied in simulations are given in framed boxes. $b$. Schematic of the Wheatstone bridge with piezoresistors $(R 1, R 2, R 3, R 4)$ and the corresponding nodes for the excitation voltage $(U+, U-)$ and the output signal $(M+, M-)$. c. Photograph of SP with longitudinal piezoresistors connected to a PCB for characterization.

In an ideal case, the single SP deflects in only it one sensitive $z$-direction (Fig. 1b). In the other directions ( $x$ and $y$ ), it has to be of infinite stiffness and able to transmit forces. In practice, the structure may deform slightly also in the $x$ - and $y$ directions, which could impair the orthogonality of the three SPs. Nevertheless, these deformations were considered negligible if a ratio of minimally 100:1 between the stiffness in $x$ - or $y$-directions and $z$-direction could be guaranteed. Deformations due to torsional loads were not considered in the simulation and in the experimental characterization of the SPs. In order to optimize its geometrical dimensions, only single SPs were simulated. Therefore, the SP geometry was parameterized by the width of the hinge/membrane $\mathrm{W}_{\text {mem }}$, its thickness $t_{\text {mem }}$ and its length $L_{\text {mem }}$ (Fig. 2a) in order to study influences on the main axis stiffnesses $\left(\mathrm{S}_{\mathrm{x}}, \mathrm{S}_{\mathrm{y}}\right.$ and $\left.\mathrm{S}_{\mathrm{z}}\right)$. All other geometric parameters (thicknesses of the spacer and of the spring substrates) were kept constant.

\section{2) Analytical vs FEM Simulation of the Single $S P$}

The bending of an SP under the effect of a force 2P (Fig. 3a) can be described in a simplified way as the bending of a individual cantilever beam with a length $l_{0}(=4 \mathrm{~mm})$ fixed at one end under the action of a force $P$ and a moment $M_{0}$ applied at the other free end (Fig. 3b). The latter inhibits the rotation of the free end of the beam so that it just deflects in one direction ( $z$-direction), which in the SP is assured by the parallelogram structure. Thanks to the moment-curvature equation from the general beam bending theory [46], relating the curvature of the beam $v_{0}^{\prime \prime}$ to the sum of the moments (Eq. (1)), the deflection in the $z$-direction (positive upward) $v_{0}$ and the slope of the deflection curve $v_{0}^{\prime}$ can be calculated by two successive integrations of $v_{0}^{\prime \prime}$ over $x$ (Eq. (2), and Eq. (3)).

$$
\begin{gathered}
E_{0} I_{0} v_{0}^{\prime \prime}(x)=\sum M(x)=M_{0}-P\left(l_{0}-x\right) \\
E_{0} I_{0} v_{0}^{\prime}(x)=\left(M_{0}-P l_{0}\right) x+P \frac{x^{2}}{2}+C_{1} \\
E_{0} I_{0} v_{0}(x)=\left(M_{0}-P l_{0}\right) \frac{x^{2}}{2}+P \frac{x^{3}}{6}+C_{1} x+C_{2}
\end{gathered}
$$

The beam end does not rotate, which is reflected by the boundary conditions $v_{0}^{\prime}(0)=0, v_{0}^{\prime}\left(l_{0}\right)=0$. With these conditions $M_{0}$ is given as

$$
M_{0}=\frac{P l_{0}}{2}
$$

To calculate $v_{0}(x)$, the inertial moment $I_{0}$ has to be determined. The beam can be divided in three-segments (noted I, II and III), which correspond to the hinges and the boss (Fig. 3a). Each have a constant inertial moment $I_{i}$, determined by $h_{i}$ the thickness of the respective beam section. Note that, the tapering of the beam section at the points $\mathrm{A}, \mathrm{B}, \mathrm{C}$, and $\mathrm{D}$ was considered to be neglectable and the same width $b_{I}=b_{I I}=b_{I I I}$ is assumed for all segments.

$$
I_{i}=\frac{b_{i} h_{i}^{3}}{12}
$$

The deformation of each segment can be calculated by considering a cantilever beam $i$ with a length $l_{i}$ under the action of a force $P$ and a moment $M_{i}$ applied at its free end. The moments $M_{i}=M_{0}-P\left(l_{0}-x_{i}\right)$ are deduced from Eq. (1) by setting $x_{i}$ to the $x$-coordinate at the respective points $\mathrm{B}, \mathrm{C}$ or $\mathrm{D}$, corresponding to the free end of beam $i$ (Fig. 3a). As before, the deflection $v_{i}$ and the slope of the deflection curve $v_{i}{ }^{\prime}$ can be obtained by two successive integrations of $v_{i}^{\prime \prime}$ over $x$. To determine the constants $C_{1}$ and $C_{2}$ for each segment, the boundary and continuity conditions of each beam have to be set. The derivation of $v_{0}(x)$ which consists of the $v_{i}$ for for each $x$ segment is not given here.

Instead, $v_{0}\left(x_{D}\right)$ the z-deflection at point $\mathrm{D}$ (the maximum deflection of the complete construction) is calculated. The maximum deflection of the beam I and III are equal because of the design symmetry $\left(l_{I}=l_{I I I}\right.$ and $\left.h_{I}=h_{I I I}\right)$. The beam II with a length $l_{I I}=l_{0}-2 l_{I}$ can be considered as rigid $\left(h_{I I} \gg h_{I}\right)$ 
and only rotates by an angle defined by $v_{I}^{\prime}\left(l_{I}\right)$. In combination with the deflection $v_{I}(x)$ and the slope of beam $\mathrm{I} v_{I}{ }^{\prime}(x)$, for which $C_{1}=C_{2}=0, v_{0}\left(x_{D}\right)$ results as

$$
v_{0}\left(x_{D}\right)=2 \cdot v_{I}\left(l_{I}\right)+l_{I I} \cdot \tan \left(v_{I}^{\prime}\left(l_{I}\right)\right)
$$

By successive substitutions of $v\left(l_{I}\right)$ and $v^{\prime}\left(l_{I}\right)$ with the Eq. (2), (3), (4), and (5), $v_{0}\left(x_{D}\right)$ can be expressed as function of the beam geometry, it elastic property and the applied force. In addition, $\tan \left(v^{\prime}\left(l_{I}\right)\right)$ can be approximated with $v^{\prime}\left(l_{I}\right)$, for small angles $v^{\prime}\left(l_{I}\right)<0.17 \mathrm{rad}\left(\approx 9.7^{\circ}\right)$ the deviation stays under $1 \%$.

$$
v_{0}\left(x_{D}\right)=2 P \cdot \frac{\left(-4 l_{I}^{3}+6 l_{0} l_{I}^{2}-3 l_{0}^{2} l_{I}\right)}{E_{I} b_{I} h_{I}^{3}}
$$

The deflections $v_{0}(x)$ and $v_{0}\left(x_{D}\right)$ were computed for a SP with $l_{I}=L_{\text {mem }}: 0.35 \mathrm{~mm}, \quad b_{I}=W_{\text {mem }}: 3.8 \mathrm{~mm}, \quad h_{I}=t_{\text {mem }}$ : $0.0191 \mathrm{~mm}$. and with a Young's modulus $E_{100}=130 \mathrm{GPa}$ defined for the silicon with a (100) crystal orientation [47].

The simulations of the complete SP were carried out in the simulation tool Ansys using the same boundary conditions and meshing settings as in earlier work [26]. The FEM simulations were carried out assuming an isotropic material (with $E_{100}$ in all directions) and assuming the anisotropic material properties of (100) oriented silicon [47]. To compare the analytical and the FEM simulation models, a deflecting force $2 P$ of $50 \mathrm{mN}$ in $Z$ direction was assumed. To relate these results to the reality, the deflection of SPs with such geometry for the force $2 P$ was determined from experimentally obtained stiffnesses (presented in II.D.2), Fig. 9). Results of analytical and simulation models together with the experimental data are compared and given in Fig. 3c.

Between $v_{0}\left(x_{D}\right)$ and $v_{0}\left(x_{D}\right)$, a negligible difference of $0.02 \%$ can be observed, validating the approximation done for $v_{0}\left(x_{D}\right)$ (Eq. (7)). The FEM simulation for isotropic material agrees by difference of $1.9 \%$ with the analytical computation $\left(v_{0}(x)\right.$, and $\left.v_{0}\left(x_{D}\right)\right)$, which can be explained with the limitations of the bending theory (see hypotheses of bending theory for a beam [46]). In comparison with the experiment, the analytical results are overestimated by $25 \%$. The results of the FEM simulation for anisotropic material differ up to $22 \%$ from the analytical one but agree within the tolerance range of the experiment. In a similar study on a silicon based system [47], it has been shown that with the right assumption of material properties, FEM simulations provide better predictions than analytical methods. For that reason, FEM simulation were chosen for the following parameter variation study. However, the approximated sensitivity of the stiffness in $z$-direction for variations of the geometrical SP parameters can be deduced from Eq. (7) as

$$
S_{z}=\frac{2 P}{v_{0}\left(x_{D}\right)}=\frac{E_{100} W_{\text {mem }} t_{\text {mem }}^{3}}{-4 L_{\text {mem }}^{3}+6 l_{0} L_{\text {mem }}^{2}-3 l_{0}^{2} L_{\text {mem }}}
$$

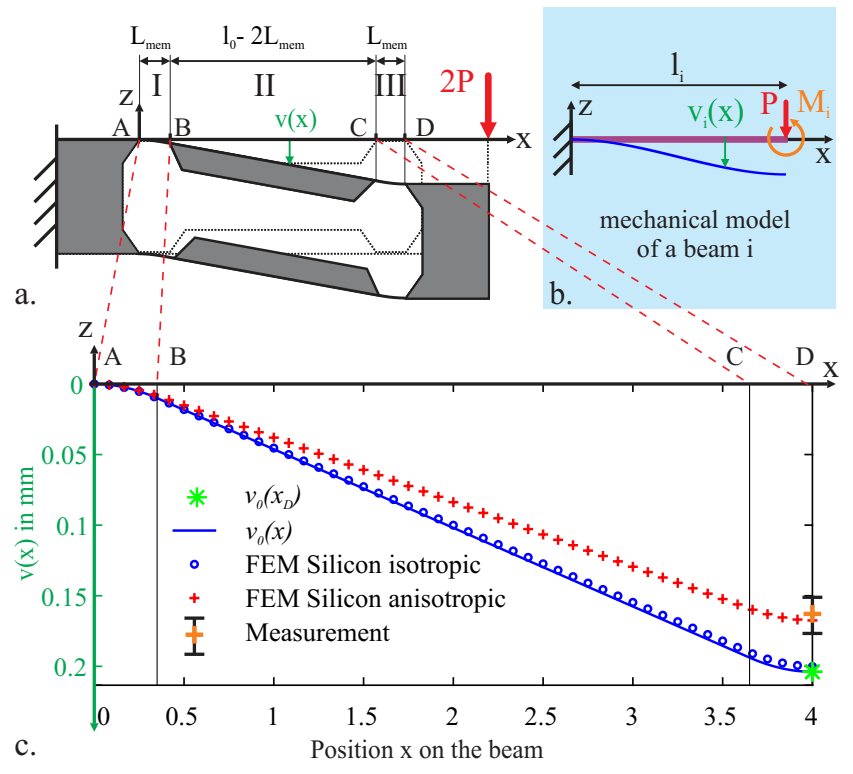

Fig. 3. a. Deformation of the SP and definition of the three segments I, II and III, b. mechanically equivalent beam segment model and, c. FEM simulated, analytically obtained and measured deflections $v(x)$ of an SP when a force of $2 P=50 \mathrm{mN}$ is applied at the free end.

\section{3) Parameter variation study}

In a similar manner as in a previous work on different microprobe designs [26], parameter variation studies were carried out in Ansys using the same boundary conditions and meshing settings and the same material properties of anisotropic silicon. For the simulation, one end of the SP was fixed and a force of $50 \mathrm{mN}$ was applied in each of the three main directions $(x, y$ and $z)$ on the other end (Fig. 1b). While one parameter was varied over a certain range $\left(t_{\text {mem }}\right.$ : between 15 and $35 \mu \mathrm{m}, L_{m e m}$ : between 250 and $450 \mu \mathrm{m}$, and $W_{\text {mem }}$ : between 3.0 and $3.8 \mathrm{~mm}$ ), the other two were kept constant. From the obtained deflections, the stiffnesses $\left(\mathrm{S}_{\mathrm{x}}, \mathrm{S}_{\mathrm{y}}\right.$, and $\left.\mathrm{S}_{\mathrm{z}}\right)$ were calculated.

In Fig. 4, the obtained stiffnesses $S_{\mathrm{x}}, \mathrm{S}_{\mathrm{y}}$ and $\mathrm{S}_{\mathrm{z}}$ are presented as a function of $t_{m e m}$ and $L_{m e m}$ for a $W_{m e m}=3.8 \mathrm{~mm}$. 


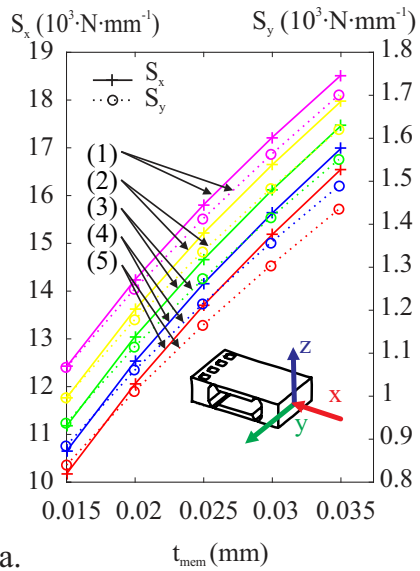

$\mathrm{S}_{\mathrm{z}}\left(\mathrm{N} \cdot \mathrm{mm}^{-1}\right)$

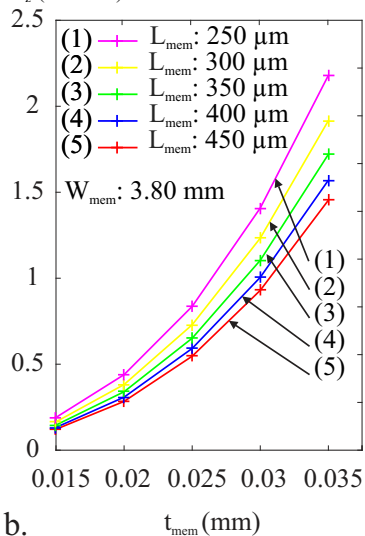

Fig. 4. Single Si-parallelogram stiffness a. in $x, y$ (hard) directions and $b$. in $z$ (soft) direction as a function of $t_{\text {mem }}$ and $L_{\text {mem }}$ for $W_{\text {mem }}=3.8 \mathrm{~mm}$, as obtained by simulations. The hard axis stiffnesses $S_{x}$, and $S_{y}$ typically differ by an order of magnitude and are therefore plotted on different scales.

In order to easily understand the sensitivities of the dimensional parameters, the simulation results were approximated on the range studied for each parameter by a fit-function $y=a \cdot x^{b}$, where $y$ represents $\mathrm{S}_{\mathrm{x}}, \mathrm{S}_{\mathrm{y}}$ or $\mathrm{S}_{\mathrm{z}}$, and $x$ the geometric parameters $W_{\text {mem }}, t_{\text {mem }}$ or $L_{\text {mem }}$. In Table 1 , the coefficients a and $\mathrm{b}$ are given for the varied parameter $x$ while values of the other geometric parameters were fixed. Results were obtained by linear regression using a logarithmic scale for $y$. For all regressions, a coefficient of determination $\mathrm{R}^{2}>0.997$ was obtained, attesting a very good fit. The geometric parameters of the elastic membrane hinges differ in their influence on the stiffnesses $S_{Z}$ and can be sorted in order of strength of influence as $t_{m e m}, L_{m e m}$ and $W_{m e m}$. The approximated scaling of stiffnesses as $S_{z} \propto t_{m e m}^{3}(\mathrm{~b}=2.91)$ and $S_{z} \propto w_{\text {cross }}(\mathrm{b}=1.00)$ can be understood when considering the Eq. (8). $L_{m e m}$ does have an inverse influence on $S_{z}$ as in Eq. (8), and for increasing $L_{m e m}$ values of $S_{z}$ converges with single beam (without a boss) results. For $S_{x}$ and $S_{y}$, complex deformations behavior of the parallelogram will occur but the simulations confirm that with a longer, slimmer and/or a thinner membrane, the stiffnesses in all directions decrease. Most important is that $S_{x}$ and $S_{y}$, are always more than 1000 times higher than $S_{z}$. Therefore, the deflections of the SP in stiff directions $x$ and $y$ are negligible, which is the basic requirement for the concept of a 3D combination of the SP. Further, a stiffness below $1 \mathrm{~N} \cdot \mathrm{mm}^{-1}$ in measurement the soft direction $(z)$ is achievable, which is important feature for microprobes. As first parameter for adjusting the soft direction stiffness $\mathrm{S}_{\mathrm{z}}$, the most sensitive value of $t_{\text {mem }}$ can be varied. Also, $L_{m e m}$ could be adjusted while considering not get too low the ratios $S_{x} / S_{z}$ and $S_{y} / S_{z}$. $\mathrm{W}_{\text {mem }}$ has a greater influence on $S_{\mathrm{y}}(\mathrm{b}=2.37)$ than on the soft direction stiffness $S_{z}(b=1$, i.e. linear). This parameter can therefore be increased to a practical maximum to assure high stiffness in $\mathrm{S}_{\mathrm{y}}$ (in practice $3.8 \mathrm{~mm}$ was later chosen).
Table 1. Fit parameters, as obtained by simulations for studying sensitivities of the hinge dimensions. The results are given for the stiffnesses in $\mathrm{N} \cdot \mathrm{mm}^{-1}$ and for the parameters given in $\mathrm{mm}$.

\begin{tabular}{|c|c|c|c|}
\hline \multicolumn{4}{|c|}{$\begin{array}{c}\text { Influence of } \mathbf{L}_{\mathbf{m e m}} \text { btw. } \mathbf{0 . 2 5 - 0 . 4 5} \mathbf{~ m m} \\
\text { for } \mathrm{t}_{\text {mem }}=0.025 \mathrm{~mm} \text { and } W_{\text {mem }}=3.8 \mathrm{~mm}\end{array}$} \\
\hline & $S_{x}=a \cdot L_{m e m}^{b}$ & $S_{y}=a \cdot L_{m e m}^{b}$ & $S_{z}=a \cdot L_{m e m}^{b}$ \\
\hline $\mathbf{a}$ & $11.3 \cdot 10^{3}$ & 899 & 0.305 \\
\hline b & -0.243 & -0.328 & -0.725 \\
\hline \multicolumn{4}{|c|}{$\begin{array}{l}\text { Influence of } \mathbf{t}_{\text {mem }} \text { btw. 0.015-0.035 } \mathbf{~ m m} \\
\text { for } L_{\text {mem }}=0.35 \mathrm{~mm} \text { and } W_{\text {mem }}=3.8 \mathrm{~mm}\end{array}$} \\
\hline & $S_{x}=a \cdot t_{m e m}^{b}$ & $S_{y}=a \cdot t_{m e m}^{b}$ & $S_{z}=a \cdot t_{m e m}^{b}$ \\
\hline $\mathbf{a}$ & $102 \cdot 10^{3}$ & $11.3 \cdot 10^{3}$ & $29.8 \cdot 10^{3}$ \\
\hline b & 0.526 & 0.593 & 2.91 \\
\hline \multicolumn{4}{|c|}{$\begin{array}{c}\text { Influence of } \mathbf{W}_{\text {mem }} \text { btw.3.0-3.8 mm } \\
\text { for } \mathrm{L}_{\mathrm{mem}}=0.35 \mathrm{~mm} \text { and } t_{\mathrm{mem}}=0.025 \mathrm{~mm}\end{array}$} \\
\hline & $S_{x}=a \cdot W_{m e m}^{b}$ & $S_{y}=a \cdot W_{m e m}^{b}$ & $S_{z}=a \cdot W_{m e m}^{b}$ \\
\hline $\mathbf{a}$ & $5.06 \cdot 10^{3}$ & 54.0 & 0.172 \\
\hline b & 0.799 & 2.37 & 1.00 \\
\hline
\end{tabular}

4) Simulation of the 3DSP

The complete 3DSP was also mechanically simulated with the same material properties and meshing parameters. To simulate the deflection of the system, the 3DSP was fixed at one end and a force of $50 \mathrm{mN}$ was applied at the free end (Fig. 1). Fig. 5a-c display the simulation results of the new 3DSP without the stylus and assuming fixed areal contacts between the SPs. A force of $50 \mathrm{mN}$ in each of the three directions $(X, Y$, and $Z$ ) was applied, which resulted in deflection of the SP in only its soft direction. In each case, only one SP deflects whereas for the other SPs, no significant deflection is recognized. For the different force directions, the deflections of the moving end vary of about $11 \%$ (between $59 \mu \mathrm{m}$ and $66 \mu \mathrm{m}$ ). The simulated deflection of a single SP by applying a force of $50 \mathrm{mN}$ in soft direction (z) amounts $56 \mu \mathrm{m}$ (Fig. 5d). Even through not directly visible, torsions of the SP may occur (as shown in Fig. 5) due to leverage-effects. This leads to a deflection of the moving end of less then $10 \mu \mathrm{m}$. Nevertheless, the simulations confirm the orthogonal working principle and almost perfect mechanical isotropy (1.1) of the 3DSP together with a low stiffness $S\left(<1 \mathrm{~N} \cdot \mathrm{mm}^{-1}\right)$. 

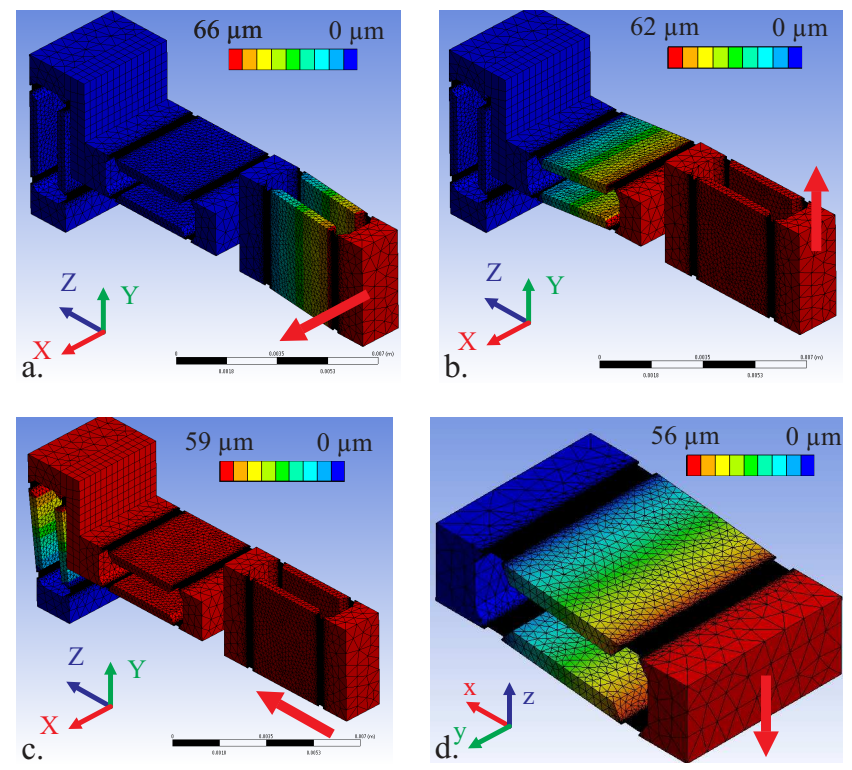

Fig. 5. a.-c. Deflection of a 3DSP in X-, Y-, and Z-direction and $d$. deflection of a SP in $Z$-direction as obtained by simulations for a force of $50 \mathrm{mN}$.

\section{B. Fabrication process of singles $S P$}

The fabrication of singles SP involved the processing of three different silicon wafers, corresponding to front spring, rear spring and spacer substrates (Fig. 2a), their bonding (Fig. 2b), and the dicing of the obtained stack. The wafer-level processing was very similar to the one for the silicon membrane based microprobe of earlier works $[22,26]$. A double-sided polished n-doped (100)-silicon wafer with a thickness of $360 \pm 25 \mu \mathrm{m}$ was used for the front and the rear wafer and with a thickness of $1000 \pm 25 \mu \mathrm{m}$ for the spacer.

On the front wafer, the piezoresistors and their contacting areas were first diffused in the silicon using a $\mathrm{p}$ - and a p+-doping with boron atoms. As diffusion source, a boron solution was applied by spin coating. The obtained film was dried and heated to $900^{\circ} \mathrm{C}$ for $30 \mathrm{~min}$ for $\mathrm{p}$-diffusion and $1100^{\circ} \mathrm{C}$ for $30 \mathrm{~min}$ for $\mathrm{p}+-$ diffusion (Fig. 6a, Step 1). Longitudinal and also transversal orientations of the resistors were fabricated and tested (Fig. 2a). After passivation of the top surface with a silicon dioxide $\left(\mathrm{SiO}_{2}\right)$ layer, the resistors were wired by metallic tracks (aluminum or gold can be used) by vias structured into the $\mathrm{SiO}_{2}$ layer. For the contacting of the sensors, $20 \mu \mathrm{m}$ thick soldering copper pads were deposited by galvanization. A silicon nitride $\left(\mathrm{Si}_{3} \mathrm{~N}_{4}\right)$ passivation layer was applied to the surface to protect the wiring during the use of the SPs (Fig. 6a, Step 2). The thin membranes were obtained by wet etching of the silicon in a $40 \%$ of potassium hydroxide $(\mathrm{KOH})$ solution at a temperature of $80{ }^{\circ} \mathrm{C}$. For this step, a hard mask made of $420 \mathrm{~nm} \mathrm{SiO}_{2}$ and $300 \mathrm{~nm}$ $\mathrm{Si}_{2} \mathrm{~N}_{3}$ layers was employed. Knowing the etch rate, the membrane thickness could be controlled by time (Fig. 6a, Step $3)$. The rear and the spacer wafer are free of electrical elements and were only etched in $\mathrm{KOH}$ as with the front wafer.

After the processing, the three different wafers were bonded together with an adhesive technique. For this bonding, a special adhesive transfer technique was used in order to deposit controlled layers of glue only on the surfaces to bond. In
Fig. $6 \mathrm{~b}$, the five adhesive bonding steps are illustrated. In the first step, a polyimide foil was coated with epoxy glue (353ND, Co. Epotek) by spin coating (4000 $\left.\mathrm{min}^{-1}, 30 \mathrm{~s}\right)$, spreading it over the foil with a constant thickness. The foil was then contact transferred to the surface of the spacer. After peeling off the foil, a thin glue layer remained. The front and the spacer were aligned to each other with the aid of alignment marks on an alignment system (EVG®620, EVG®420 from EV Group). Finally, the glue was cured at $150{ }^{\circ} \mathrm{C}$ for $1 \mathrm{~min}$. This adhesive transfer and alignment process was repeated for the rear spring and the front spring/spacer stack. Alternative bonding techniques as anodic bonding are currently investigated.

Separation of the SPs by wafer dicing (DAD320 from co. Disco) was found to create problems. Whilst sawing, the upper and lower edges of the silicon splintered. When the saw reaches the membrane, this splintering can cause cracks. Therefore, a membrane retraction was implemented on wafer-level using the Bosch process (Fig. 2a). In this way, a well-defined width of the membrane and a frame of thicker silicon that protects the membrane during dicing and handling are provided.

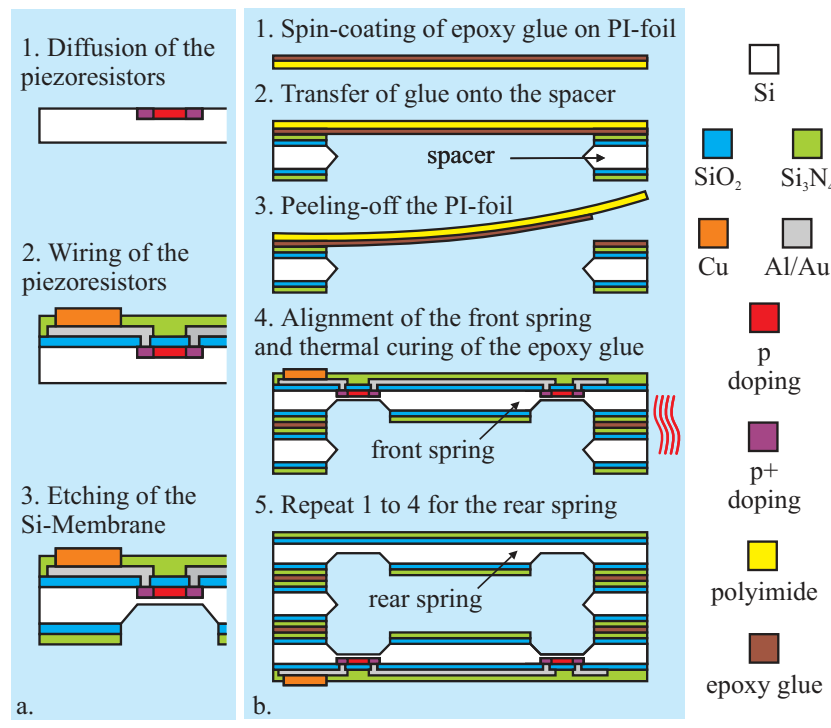

Fig. 6. a. Wafer-level fabrication of piezoresistors and silicon membranes and $b$. wafer-level adhesive bonding process with glue transfer for the fabrication of parallelograms.

\section{Assembly and contacting of SP, for a first 3DSP prototype}

In order to experimentally prove the working principle of the 3DSP, the first prototypes were built using the produced SPs with (w/) and without (w/o) ultra-thin flexible contacting foils (Fig. 7a), and then characterized (D.3)). The foil made of a thin polyimide (PI) layer transmits the supply voltages and the signals of single SPs without disturbing the motions of the 3DSP's free end. The fabrication of the PI foil consisted of the spinning and curing of a $6 \mu \mathrm{m}$ PI layer on a glass wafer followed by a sputtering of $2 \mu \mathrm{m}$ of copper onto it. After a photolithographic structuring of the copper tracks, the PI was cut using a femtosecond laser. The foil was finally peeled from the glass wafer (Fig. 7b). 


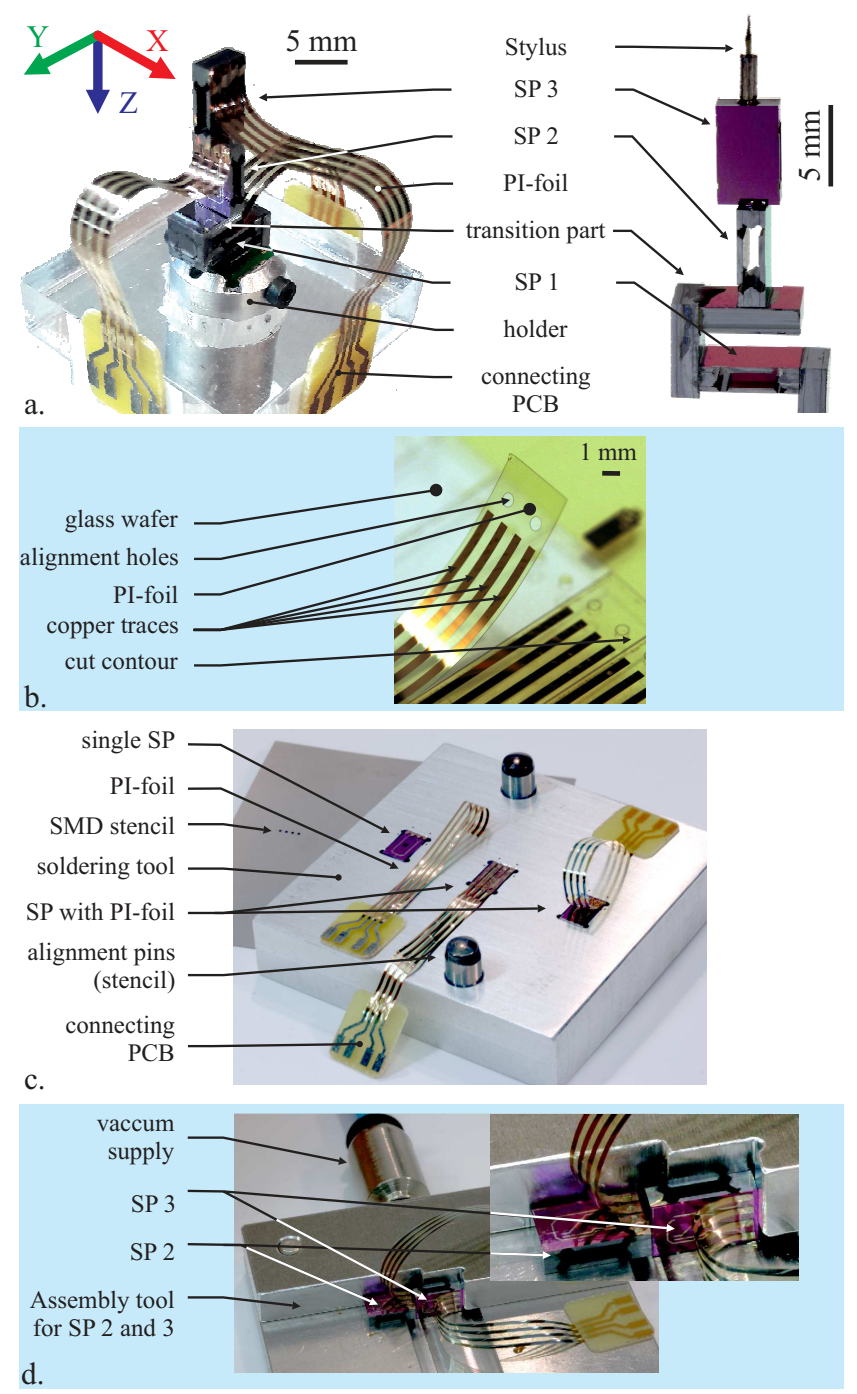

Fig. 7. a. First prototype of the 3DSP with and without PIfoil for wiring, $b$. detail view showing the foil peel-off from the glass wafer after processing and laser cutting, $c$. assembly of SP and PI-foil with soldering tool, and $d$. adhesive assembly of SP3 with SP2 using a vacuum assisted tool.

Each SP was assembled with a polyimide (PI) foil by using a soldering tool (Fig. 7c). Solder paste (CR11 from EDSYN Inc.) was applied onto the SP copper-pads by a stainless steel stencil (holes $500 \times 500 \mu \mathrm{m} 100 \mu \mathrm{m}$ thick), which was aligned to the SPs using alignment pins. The holes of the stencil and pads were perfectly superimposed. After that, the foils were placed and held in the right position on a hotplate at a temperature of $130^{\circ} \mathrm{C}$ during the melting time. To facilitate the connection with the evaluation electronics, connecting PCBs were soldered to the other end of the PI-foil.

The three SPs with soldered foil and some silicon transition parts (as shown in Fig. 7c) were assembled to form a 3DSP. For each gluing step, an assembly tool was employed to hold the parts in place by using vacuum (Fig. 7d) during the curing of the epoxy glue 353ND.

\section{Experimental evaluation}

1) Experimental setup and analysis method

For the analysis of the sensors, a linear stage (M531.5iM from PI GmbH with a resolution of $0.1 \mu \mathrm{m}$ and a stroke up to $306 \mathrm{~mm}$ $[48,49])$ controlled by a LabVIEW program was used for controlled deflection (of single SP and of 3D system) [22]. The characterization of the mechanical behavior was carried out using a calibrated load cell (KD78 from ME-Messsysteme $\mathrm{GmbH}$ ). This provides a measuring range of $1000 \mathrm{mN}$ with an accuracy class of $0.1 \%$.

During a stepwise deflection of the systems, the position of the stage, the force and the sensor voltage were recorded. As the load cell deflects, a preliminary calibration was applied to determine the relation between the measured force and its deflection (Stiffness of $5.52 \mathrm{~N} \cdot \mathrm{mm}^{-1}$ )[22]. The sensor voltages were acquired with the help of a data acquisition board (PCI 6289) from NI and data acquisition-modules (DAQP-BRIDGEB from Dewetron Inc., Gain 10). The latter are specially developed for the conditioning of signals provided by a Wheatstone bridge and also deliver the needed excitation voltage $(5 \mathrm{~V})$. From the recorded data, the force, the signal response and the deflection of the SP were extracted for further analysis. All measurements were carried at a room temperature $\left(22.5 \pm 3{ }^{\circ} \mathrm{C}\right)$.

The applied forces (in $\mathrm{mN}$ ) and the output signals expressed relative to the excitation voltage of the Wheatstone bridges (in $\mathrm{mV} \cdot \mathrm{V}^{-1}$ ) were recorded and a standard deviation $\sigma$ of these signals over $10 \mathrm{~min}$ was obtained as $0.183 \mathrm{mN}$ and respectively as $0.01 \mathrm{mV} / \mathrm{V}$ (@5V supply). $\pm 3 \sigma$ can be considered as noise level, which leads to a noise of $\pm 0.549 \mathrm{mN}(1.1 \mathrm{mN})$ for the force and $\pm 0.06 \mathrm{mV} \cdot \mathrm{V}^{-1}\left(0.12 \mathrm{mV} \cdot \mathrm{V}^{-1}\right)$ for the sensor signal.

Linear regression for data of applied forces or output voltages in dependence of deflections resulted in $\mathrm{R}^{2}$ above 0.999 .

A relative linearity error $d_{l i n} \%$ is defined as the maximum deviation of the signal from the linear fit in relation to the upper limit of the measurement range (R.O.) for force transducers [50]. Instead of the maximum deviation, the $3 \sigma$-values of the distribution around the linear fit were taken for better statistical representation. To enable an easy comparison between different measurements, the R.O. was always set to $100 \mathrm{mN}$ for the mechanical characterization and to $100 \mathrm{mV} \cdot \mathrm{V}^{-1}$ for the sensing. 2) Single SP characterization

The mechanical and the sensing behavior of fabricated single SPs were characterized. In Fig. 8a, the force is given as a function of the SP's deflection. Corresponding forces were measured for the deflection in the three directions $(x, y$, and $z)$. The measured behavior confirms the simulation results. However, experimentally obtained $S_{z}$ is only about 300 times smaller than $S_{x}$ and $S_{y}$, and not 1000 times, as expected from simulations. This can be explained with the limited precision of the gauge. At a measured force of $100 \mathrm{mN}$, the deflections of the SP should be about $10 \mathrm{~nm}$, in accordance with simulations, which was not possible to measure with the actual setup. An important result is the proof of perfect linearity of the mechanical behavior without any hysteresis over a deflection range up to $200 \mu \mathrm{m}$ (forward and backward curves are superposed for all directions). The mechanical response in $z$ direction is characterized by a $d_{\text {lin }}$ of $1.0 \%$, which corresponds to a maximum deviation from linear response of $1.0 \mathrm{mN}$. This 
deviation is mainly due to the signal noise of the load cell (KD78) used for the characterization (II.D.1).

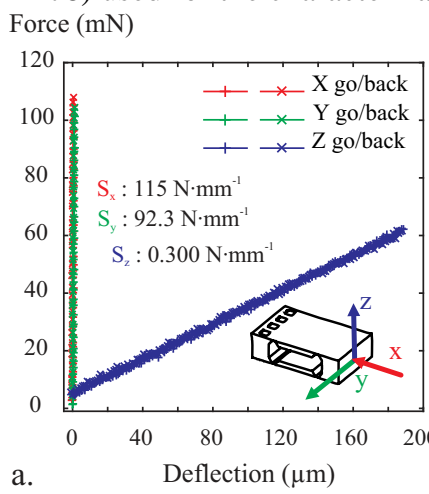

Output voltage $\left(\mathrm{mV} \cdot \mathrm{V}^{-1}\right)$

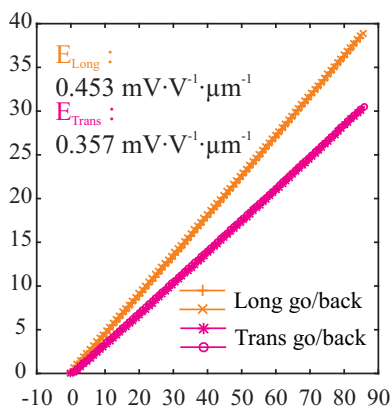

Force $(\mathrm{mN})$

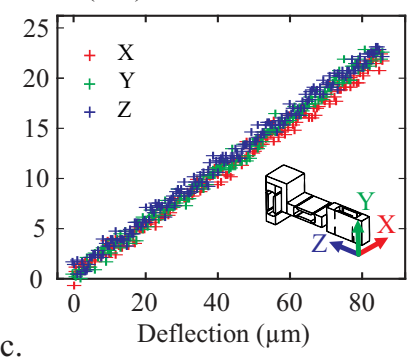

b. Deflection in z-direction $(\mu \mathrm{m})$

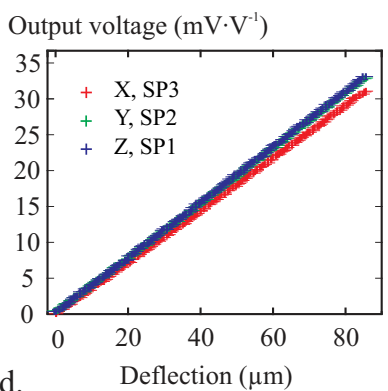

Fig. 8. a. Force versus deflection measurement for a single $S P$ in $x-, y-$, and $z$-direction, $b$. signal versus $z$-deflection measurement for longitudinal and transversal piezoresistor arrangements, $c$. force-deflection measurement, and $d$. signal-deflection measurement for a 3DSP prototype in $x$-, $y$-, and z-direction.

Mechanical characterization was carried out for SP with three different membrane lengths and a membrane thickness of $19.1 \mu \mathrm{m}$ measured on the side using a 3D laser scanning confocal microscope (VK-X Series, Keyence). In Fig. 9, the simulated values are compared to values measured with a standard deviation $\sigma<0.008 \mathrm{mN} \cdot \mathrm{mm}^{-1}$. The simulation values practically agree with the measured ones (less than $3 \%$ deviation). The use of SOI wafers providing well defined membrane thicknesses could in future allow to reduce processing variations.

Fig. 9 also gives the operation ranges for SPs (maximum deflection before fracture) with different membrane lengths at the thickness of $19.1 \mu \mathrm{m}$. For this experiment, eight samples were deflected until fracture and maximum deflections exceeding $400 \mu \mathrm{m}$ could be measured. The mean values and the standard deviations $\sigma<100 \mu \mathrm{m}$ are given. The use of such SP in a 3DSP would expand the operation range for more than four times against silicon membrane based microprobes reported so far $[15,22,25,26]$.

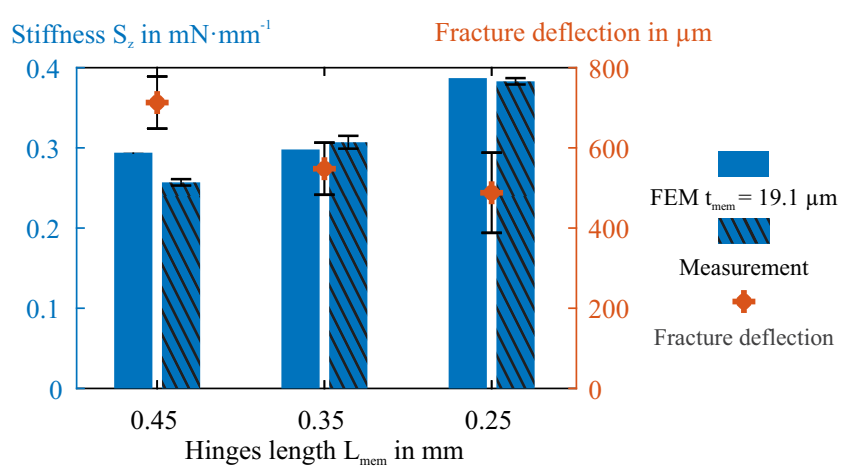

Fig. 9. Simulated and measured stiffness values together with the corresponding deflection in $\mathrm{Z}$-direction leading to fracture for single SPs with a membrane thickness of $19.1 \mu \mathrm{m}$.

The sensing characteristics for longitudinal and transversal piezo-resistor arrangements at z-direction deflection are given in Fig. 8b. As for the mechanical behavior, the electrical response is also perfectly linear and without hysteresis, which is a real benefit for the evaluation of the sensors' signals. The relative linearity error $d_{\text {lin }}$ are for longitudinal arrangement $0.13 \%$ (R.O. $100 \mathrm{mV} \cdot \mathrm{V}^{-1}$ ) and for the transversal arrangement $0.14 \%$, which correspond to maximum deviations of $0.13 \mathrm{mV} \cdot \mathrm{V}^{-1}$ and $0.14 \mathrm{mV} \cdot \mathrm{V}^{-1}$. The obtained sensitivities $\mathrm{E}$ are sufficient to enable submicrometer precision measurements. The difference between both arrangements can be explained by the distribution of strains in the membrane. The longitudinal arrangement already profits from high strains located at the border of the membrane (towards the outside of the SP). To further optimize the sensitivities, the resistors can still be repositioned.

3) 3DSP sensor characterization

Like the single SPs, the mechanical stiffnesses and sensitivities of the assembled 3DSP prototypes (w/ and w/o foil, see Fig. 7a) were determined. Fig. $8 \mathrm{c}$ and d displays the mechanical and electrical behavior of the 3DSP prototype $\mathrm{w} /$ foil wiring for all three directions $(X, Y$, and $Z)$. In Table 2, the corresponding stiffnesses $S_{w / \text { foil }}$ and $S_{w / o \text { foil }}$ and sensitivities $E_{w / \text { foil }}$ are listed. A perfectly linear $\left(d_{\text {lin }}<0.9 \%\right)$ and isotropic (anisotropy $<1.06$ ) mechanics as predicted by analytical and simulation models is experimentally confirmed (Fig. 8c) with a stiffness $<0.300 \mathrm{~N} \cdot \mathrm{mm}^{-1}$ for both prototypes $\mathrm{w} /$ and w/o foil wiring. The assembly method and the adhesive material do not deteriorate the mechanical behavior of the single SPs $\left(d_{\text {lin }}\right.$ of $1.0 \%$, see II.D.2). The use of the PI-foil does not affect the mechanical behavior of the system. Both prototypes present almost identical mechanical behavior with less than $2 \%$ difference for the anisotropies. The stiffness differences can be explained by the use of SPs with different geometries.

By deflecting the moving end of the 3DSP in each direction (X, $\mathrm{Y}$, and Z), the corresponding SP (e.g. SP 1 for $\mathrm{Z}$-direction) provides a perfectly linear $\left(d_{\text {lin }}<0.17 \%\right)$ electrical response (Fig. 8b). Similar to the mechanical behavior, the sensing behavior is also isotropic (max. anisotropy: 1.07, s. Table 2). The cross talk between the three SPs (e.g. the response of SP 2 for $\mathrm{z}$-direction) was found to be between $4.3 \%$ and $7 \%$. The stepwise assembly of this prototype (II.C) may result in uncertainties in SP orientation and in a non-perfect 
orthogonality of the kinematic. A misalignment of $1^{\circ}$ will result in $1.7 \%$ cross talk. Also, the manual fixation of the microprobe in the measurement setup can influence this measurement.

Table 2. Measured stiffnesses $S$ and sensitivities $E$ in $X$-, $Y$ - and $Z$-direction for the 3DSP prototypes $w /$ and $w / o$ foil.

\begin{tabular}{cccc}
\hline Direction & $\begin{array}{c}\boldsymbol{S}_{\boldsymbol{w} / \text { ofoil }} \\
\text { in } \mathbf{N} \cdot \mathbf{m m}^{-\mathbf{1}}\end{array}$ & $\begin{array}{c}\boldsymbol{S}_{\boldsymbol{w} / \text { foil }} \\
\text { in } \mathbf{N} \cdot \mathbf{m m}^{-\mathbf{1}}\end{array}$ & $\begin{array}{c}\boldsymbol{E}_{\boldsymbol{w} / \text { foil }} \\
\text { in } \mathbf{~} \mathbf{V} \cdot \mathbf{V}^{-\mathbf{1}} \cdot \boldsymbol{\mu m}^{-\mathbf{1}}\end{array}$ \\
\hline $\mathbf{X}$ & 0.280 & 0.239 & 0.349 \\
\hline $\mathbf{Y}$ & 0.290 & 0.247 & 0.365 \\
\hline $\begin{array}{c}\text { max. } \\
\text { anisotropy }\end{array}$ & 0.300 & 0.248 & 0.369 \\
\hline
\end{tabular}

\section{ROBUST ISOTROPIC 3D MICROPROBE FOR INDUSTRIAL USE}

The fabrication and handling of the presented prototype with the PI foils demands very careful handling, which is incompatible with an industrial environment where fast, easy and robust use but still very good reproducibility is necessary. Therefore, a new assembly concept for the 3DSP was developed in order to get a compact probing system, which can fit in a $\varnothing 11 \mathrm{~mm}$ housing.

\section{A. Concept of robust interposer based assembly}

In the following, the concept, design, fabrication of the SPs and interposers (IP), and their assembly and interfacing are detailed. 1) Assembly and interfacing

The assembly of orthogonal SPs and the wiring of each SP are the key challenges for the construction of the 3DSP. To provide compactness, robustness and the necessary wiring, the three SPs were assembled with the help of four interposers, as seen in Fig. 10a. The IP0 presents the mechanical and electrical interface (eight contacting pads) of the 3DSP to the outside (Fig. 10b). In Fig. 10c, the rear and front of the three SPs, together with the IPs, are schematically displayed with the supply voltage and signals needed for the 3DSP operation. From each SP a signal track must run to the fixed end (IP0) and pass the intermediate parts (SP and IP). Only one excitation voltage (U+, U-; blue and red tracks) supplies the three SPs in order to reduce the wiring effort. This voltage is transmitted from IP0 to SP3 across the fronts of SP1 and SP2 and across IP1, IP2, and IP3. To evaluate the deflection of each SP, the measurement voltages $\left(\mathrm{M}_{\mathrm{i}}+, \mathrm{M}_{\mathrm{i}}-\right)$ pass on the rear of SP2 and SP1 to reach IP0. Mechanical and electrical-interfaces on the IPs for the assembly and the contacting of each SP were provided to assure undisturbed mechanical force transmission and signal transmission from one SP to the subsequent one. Four conductive tracks were placed on either side of the SPs to allow signal transfer and mechanical symmetry.

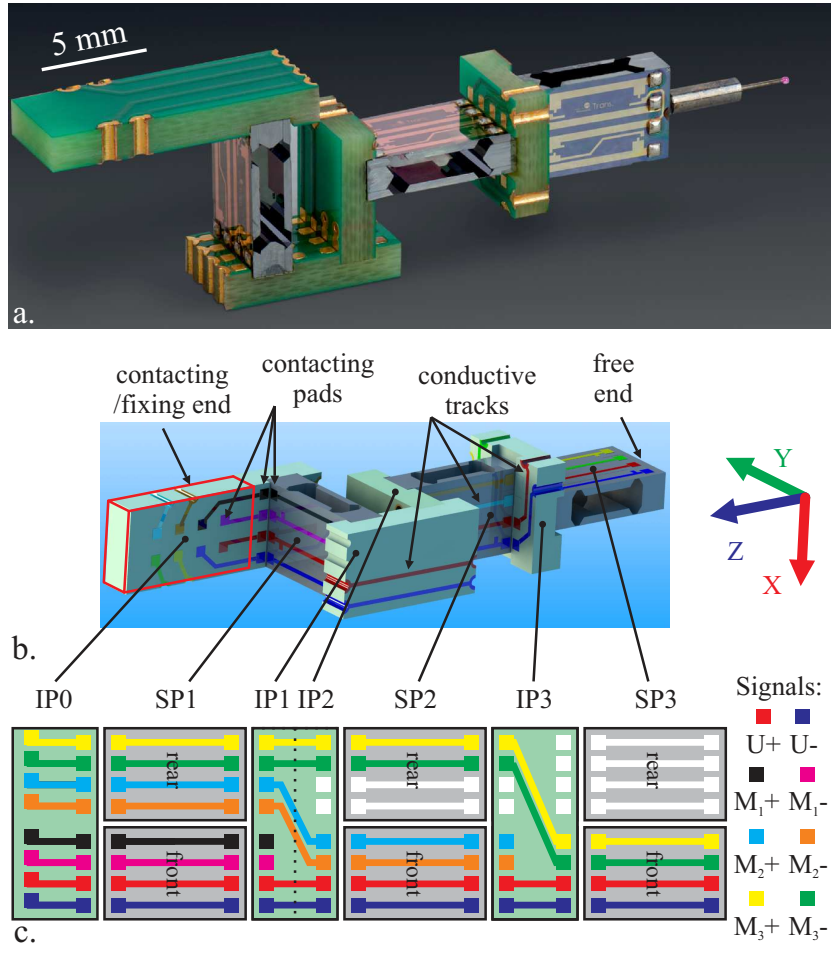

Fig. 10. a. Photograph of the new 3D silicon based

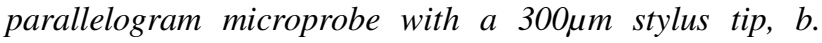
assembly and wiring of the three SPs with interposers (IPS), and $b$. diagram illustrating the electrical signal circuit.

2) Design of the SP for robust assembly

The design of a SP with longitudinal orientated piezoresistors is detailed in Fig. 11a and b. The order of the Wheatstone signals on the front of the SP was modified. The excitation voltage pads (U+, U-) were separated from the measurement pads (M+, M-). To permit a transmission of signal on the front $\left(\mathrm{U}+, \mathrm{U}_{-}\right)$and rear $\left(\mathrm{M}_{\mathrm{i}^{+}}, \mathrm{M}_{\mathrm{i}^{-}}\right)$of the SP, pass-through tracks with contacting pads were added. With the proposed design, the SP is electrically and mechanically symmetric but only two passthrough tracks are used on the front. During the fabrication of these new SPs, gold was employed instead of aluminum. This change made the fabrication easier and more reliable. Furthermore, to protect the copper pads from corrosion, the pads were gold-plated by using a golding bath (Tifoo GoldStar).

Fabrication tolerances can induce some variations of the SP properties. The electrical sensitivity may vary with non-perfect uniformity of the piezoresistor diffusion and with the quality of contacting the diffused tracks with the metallic tracks. The stiffness may vary, as shown in II.A, with geometric variations especially with the membrane thickness, which has to be controlled during the etching process. The use of SOI wafers could improve the reproducibility of membrane thickness. Also, the deflection ranges are dependent on the quality of the membrane. During the fabrication, some cracks can be initiated in the membrane and an optical inspection is necessary. 

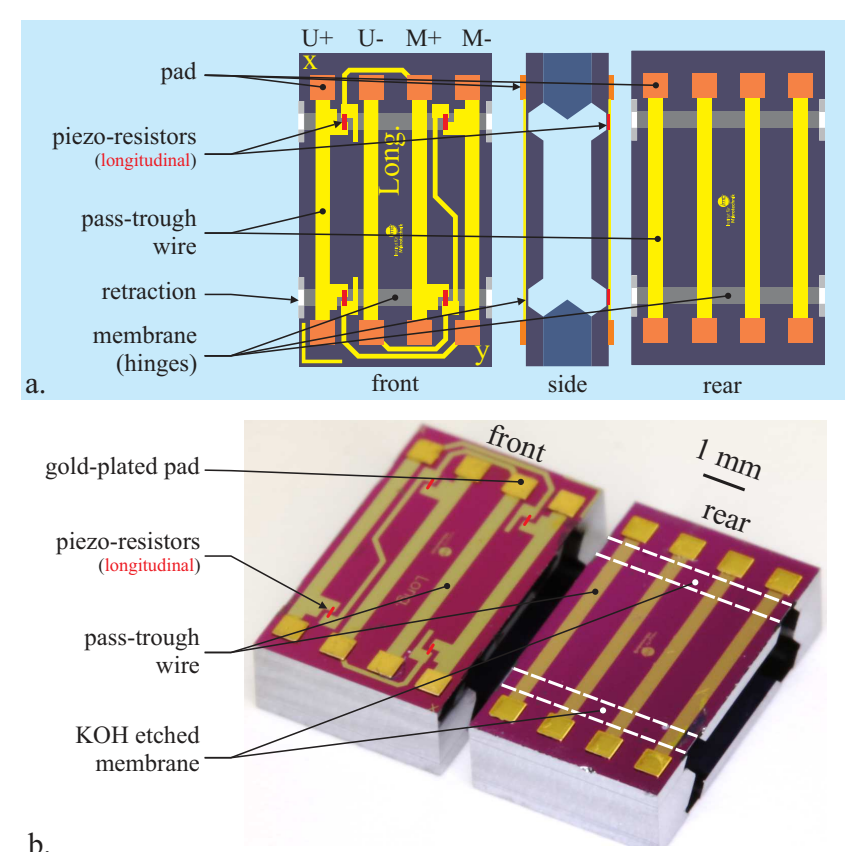

b.

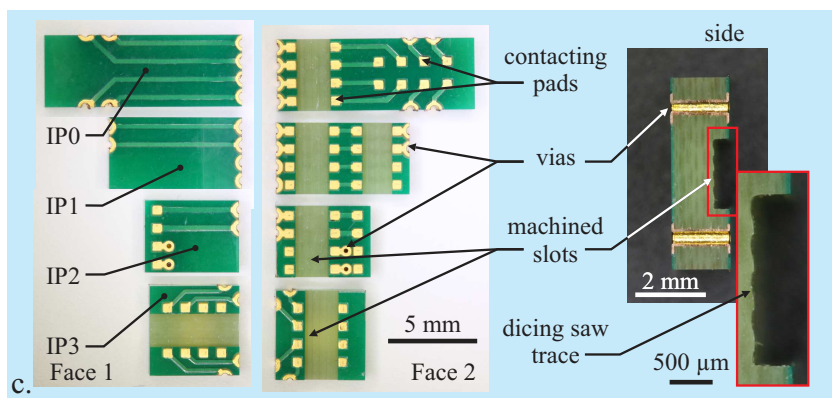

Fig. 11. Detail views of the components of the microprobe assembled with interposers: $a$. front, rear and side view of the new SP design with pass-through tracks, b. photograph of new SPs, and c. face 1, face 2 and side view of the interposers made of FR4

\section{3) Interposers fabrication}

In the first prototyping version, the IPs were fabricated from commercially fabricated $1.6 \mathrm{~mm}$ thick PCB in FR4 (glassreinforced epoxy laminate material), which was machined and subsequently separated with a wafer dicing saw (II.B). The advantages of this technique were the low fabrication price and time, as well as the benefit of using industrial techniques with high quality vias fabrication. IPs made out of silicon, glass or ceramics has not been investigated yet.

In Fig. 11c, both faces and a side view of the fabricated IPs are presented. The machined insertion slots, present on each IP, offered gluing and positioning aid during the assembly. Through this plug connection, the connecting pads of the IP and the SP are closer, which simplifies soldering. The dicing of the grooves proceeded with a $0.6 \mathrm{~mm}$ thick saw blade. To achieve the required slot width (here $1.80 \mathrm{~mm}$ ), the process was repeated 4 times for which the saw position was incremented by $400 \mu \mathrm{m}$. In Fig. 11c, the traces from the blade for each repetition can still be observed. These structures were about $50 \mu \mathrm{m}$ deep but do not cause a problem, as the bottom of the slots were not used as a positioning surface. To pass the signals from one face of the IP to the other one, half cut $\varnothing 500 \mu \mathrm{m}$ vias were used. In the PCB-layout on Eagle 7.5, the number of vias was minimized by placing them on the cut line between two IPs. In this way, during part separation using a $200 \mu \mathrm{m}$ thick blade (needed to cut the $1.6 \mathrm{~mm}$ thick PCB), the vias were split and served for both adjacent parts. Through this technique, a large number of IPs was placed on one $100 \mathrm{~mm} \times 100 \mathrm{~mm}$ PCB-plate (about 50 of each).

4) Assembly of the 3DSP: gluing and soldering

The SPs and IPs were assembled in a special tool (Fig. 12a and b) with glue (353ND, Epotek, dispensed via a needle tip). The parts were kept in position by vacuum fixation during the curing of the glue on a hotplate $\left(5 \min @ 180{ }^{\circ} \mathrm{C}\right)$. This assembly tool comprises positioning surfaces in order to get a precise orientation of the SPs to each other. The assembly in one-step granted advantages of time and repeatability compared to individual assembly of single parts.

After the glue was cured, the SPs were contacted to the IPs by manual soldering (Fig. 12c). Solder bumps were deposited on the SP-pads (front and rear) (zoom Fig. 12b) using a stencil, which is presented in Fig. 7c. The proposed assembly process could be automated for larger quantities.

The stylus was then glued with the epoxy adhesive already used for previous bonding on the free end. Styli with tip diameters of $300 \mu \mathrm{m}$ to $120 \mu \mathrm{m}$ are commercially available. For other geometries, a tungsten carbide electrode can be eroded with a $0.2 \mathrm{~mm}$ diameter wire on a $\mu$ EDM-machine (SARIX SX-200HPM) [51, 52]. With this technique, a wide variety of tips is possible to realize, including those with a $50 \mu \mathrm{m}$ diameter.

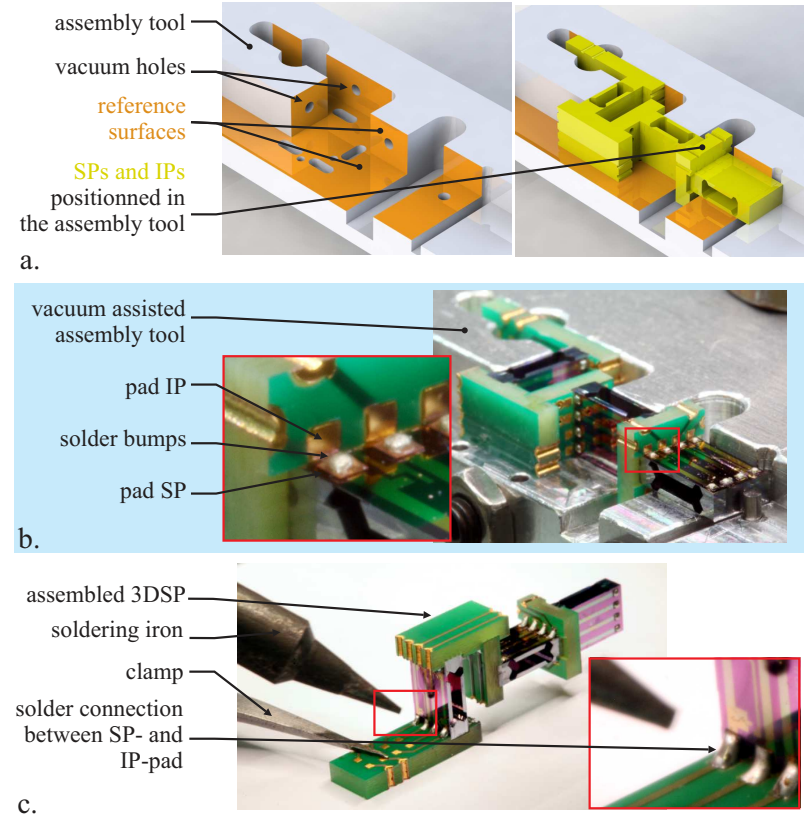

Fig. 12. Illustration of the one-step assembly and soldering of the new 3DSP: a. schematic of the vacuum assisted tool without and with assembled SPs and IPs, b. photograph showing assembly of the 3DSP using the tool, and $c$. photograph showing soldering the SPs on the IPs.

\section{5) Housing and contacting}

A housing (Fig. 13a) was developed to fix, contact and protect the microprobe during the use in a measuring machine (e.a. CMM). The housing is composed of a body, cover and nozzle. 
The 3DSP is inserted into the body and fixed by a screw. It is contacted by the help of a spring contact unit which is composed of a $2 \times 8$ spring contact array wired to external cables. The cover and nozzle close the system. This construction enables an easy exchange of microprobes. The compact system with an external diameter of $11 \mathrm{~mm}$ can be installed on a machine by a M5 screw interface. The orientation of the housing in the machine among the stylus axis can be adjusted through an orientation screw.
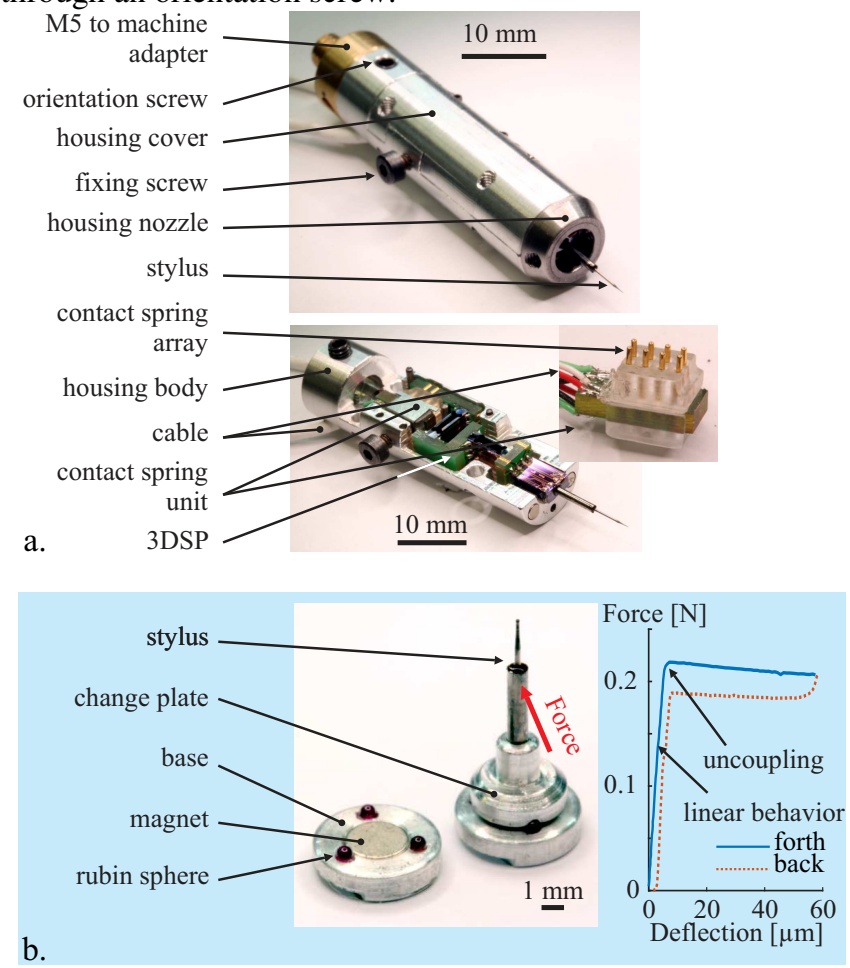

Fig. 13. a. Housing for a 3DSP, and b. stylus changing system and it mechanical behavior

As an alternative for gluing a not interchangeable stylus, a micro-changing mechanism was constructed (Fig. 13b). If a stylus change is asked (break or for different measurements tasks), the complete system has not to be changed. The change mechanism is based on a miniaturized three-V-groove coupling similar to the ones typically used in CMM for changing conventional styli $[53,54]$. It is composed of a base and a changing plate, on which a stylus is screwed. The changing plate is maintained on the base with a magnet and its position is assured by three Rubin spheres of about $\varnothing 0.8 \mathrm{~mm}$, which fit with the three-V-grooves on the plate. The deflection of the complete system linearly depends on the force (stiffness of $40 \mathrm{~N} \cdot \mathrm{mm}^{-1}$ ) up to $200 \mathrm{mN}$, where uncoupling occurs. Mounted on the free end of the 3DSP, this system offers not only stylus replacement, but also the advantage of being a mechanical protection for the 3DSP in the case of a collision or other events leading to too high deflections. The maximal force can be adjusted to the maximal deflection range of the 3DSP for instance by changing the magnetic force.

\section{B. Extended characterization of SP and $3 D S P$}

1) Characterization with triangulation sensor

The setup mentioned before (II.D.1)) was equipped with a triangulation laser sensor (LK-G10, Keyence Inc.) which enables to optically determine the displacement with a resolution of $0.1 \mu \mathrm{m}$ independent of stage positioning accuracy. Thereby it was possible to study the behavior of the SP and 3DSP for a deflection range of $\pm 200 \mu \mathrm{m}$ and during the change of deflection direction. To deflect the SP and 3DSP, obstacles were placed on either sides.

\section{2) Single SP characterization}

Three probes were deflected three times back and forth in the z-direction using two obstacles over a range of $\pm 200 \mu \mathrm{m}$. A perfect linear dependency of the output voltage from the deflection and without hysteresis can be seen in Fig. 14. The sensitivities $\mathrm{E}$ for each sample are given in Table 3. The standard deviations determined from three repetitive measurements was less than $0.10 \%$, proving an excellent repeatability of the SPs. The $d_{\text {lin }}(0.25 \%)$ is similar to the one of the previous SP version (II.D.2). The zoom in (Fig. 14b) reveals a small range of $\pm 0.25 \mu \mathrm{m}$, in which the slope is zero (dead zone). The signal values are scattered, probably due to surface interactions between the SP surface and the obstacle. However, when probing a workpiece point by point, the contact between the microprobe tip and the surface of the workpiece is assured using an asymmetric "working point". This point is defined in a deflected (for example $50 \mu \mathrm{m}$ ) state of the microprobe, whereby the accuracy of the microprobe will not be influenced by this dead zone in this probing mode. In the case of a scanning measurement mode of 3D pieces, for example scanning of a circular structure, this dead zone can be reached, which can lead to increased uncertainty. The origin of this dead zone and the influence of the measurement setup with two opposing obstacles with surface interactions will be further investigated in order to verify an accuracy better than $1 \mu \mathrm{m}$ for the scanning mode.

In Table 3, the mean and the standard deviations of $E$ obtained from the three probes are also given. A standard deviation of less than $0.4 \%$ shows how well the fabrication is reproducible. In addition, the stiffnesses $S_{z}$ were determined in the same way (Table 3). Again, a very good repeatability for the single systems and the fabrication is proven. 

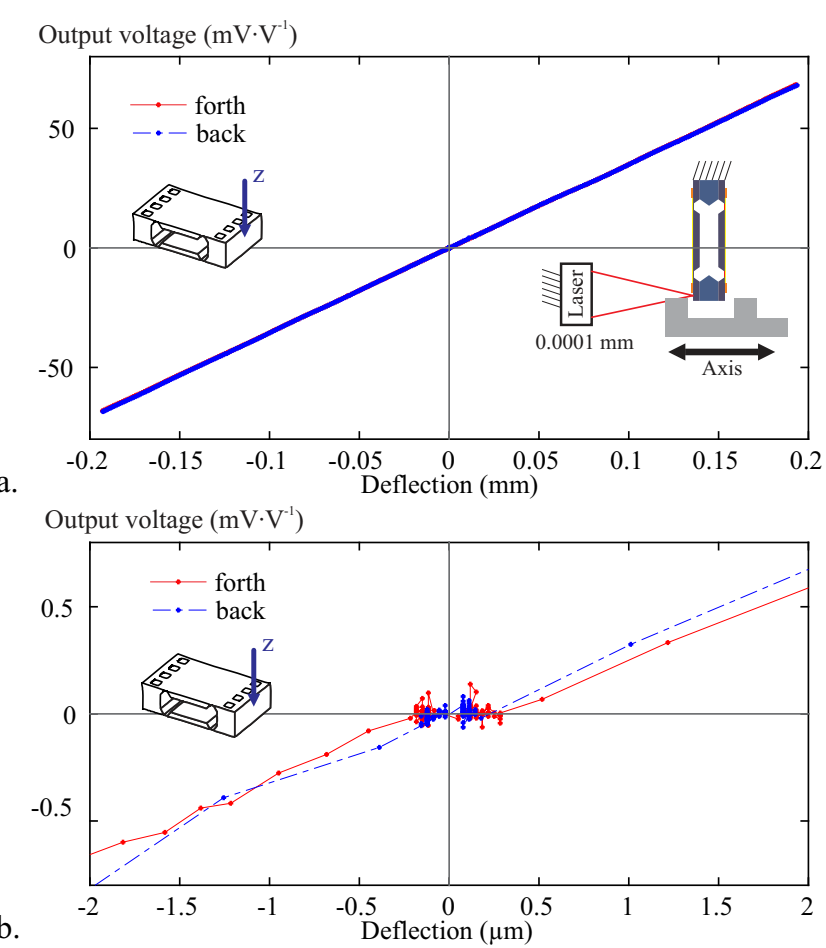

Fig. 14. a. Voltage/deflection diagram of a single SP for a $\pm 200 \mu \mathrm{m}$ deflection range (insert showing the measurement setup with two obstacles and optical determination of SP deflection), and b. zoom in around the point of deflection reversal $( \pm 2 \mu \mathrm{m})$ reveals a dead zone with a more scattered signal.

Table 3. Mechanical and sensory characterization of three SP from a single lot.

\begin{tabular}{ccc}
\hline & $\boldsymbol{E}\left[\mathbf{m V} \cdot \mathbf{V} \cdot \mathbf{\mu m}^{-\mathbf{1}}\right]$ & $\boldsymbol{S}_{\boldsymbol{z}}\left[\mathbf{N} \cdot \mathbf{m m}^{\mathbf{- 1}}\right]$ \\
\hline Probe1 & 0.353 & 0.317 \\
\hline Probe2 & 0.352 & 0.324 \\
\hline Probe3 & 0.355 & 0.320 \\
\hline Mean & 0.353 & 0.320 \\
\hline Standard deviation & 0.001 & 0.003 \\
\hline
\end{tabular}

\section{3) 3DSP characterization}

Fig. 15a and $\mathrm{b}$ show the linear relation between the deflection of the 3DSP with and without a thin attached stylus obtained by applying a force in three directions $(X, Y$, and $Z)$. For the relative linearity error, a maximal value of $0.94 \%$ was determined for all cases, which is similar to the one determined for the 3DSP prototypes $\mathrm{w} /$ and w/o foil wiring (II.D.3).
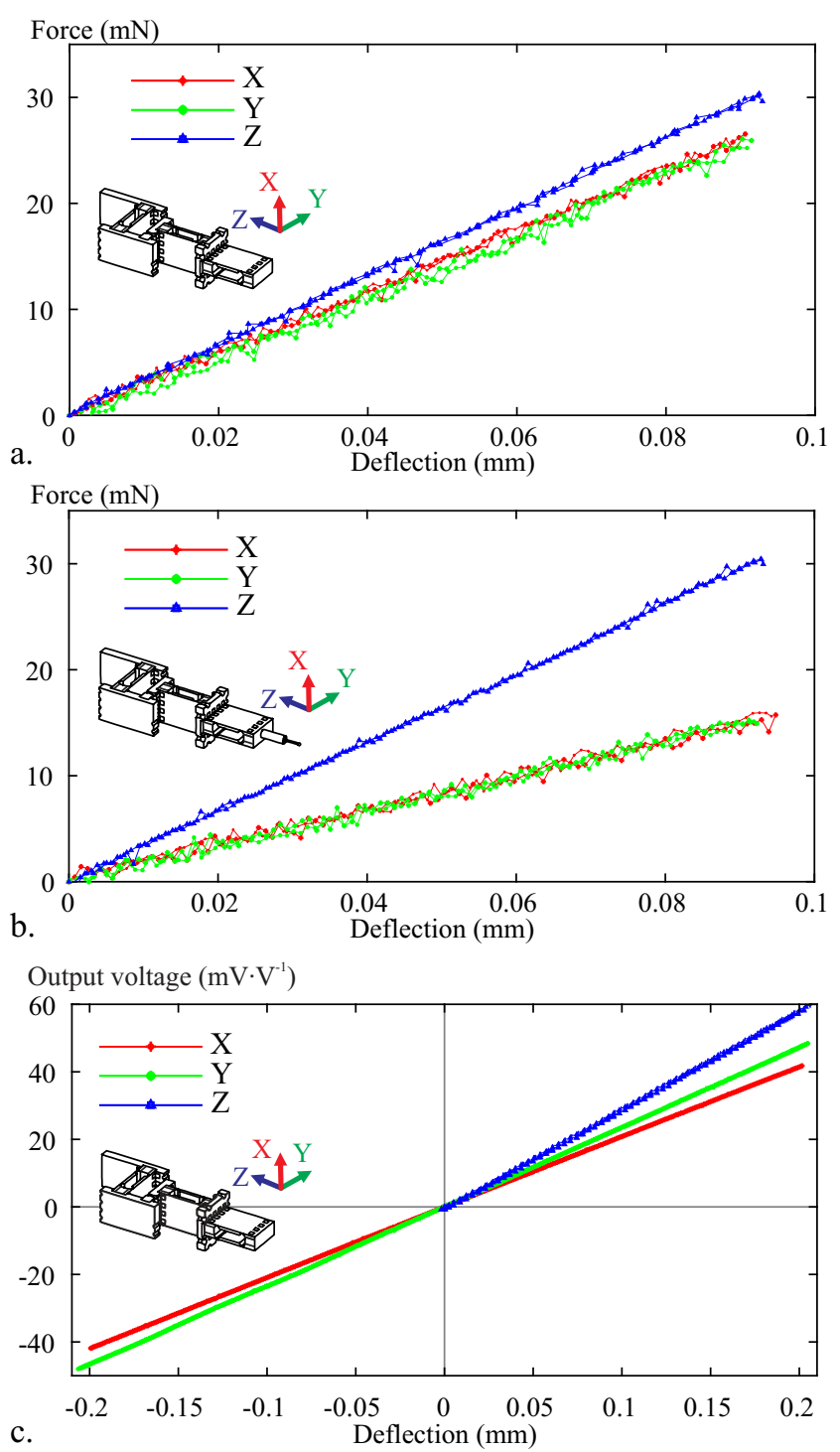

Fig. 15. Force/deflection diagram of a 3DSP for a $100 \mu \mathrm{m}$ deflection range in $X-, Y$-, and $Z$-direction: $a$. without, $b$. with stylus, and c. voltage/deflection diagram of a $3 D S P$ without stylus for a $\pm 200 \mu \mathrm{m}$ deflection range in $x$-, $y$-, and $+200 \mu \mathrm{m}$ in $\mathrm{z}$-direction.

In Table 4, the measured stiffnesses in $X$-, $Y$-, and $Z$-directions are listed. Without a stylus, the system is perfectly isotropic whereas a small anisotropy appears with a stylus. The influence of the stylus (mounted in the $Z$-direction) was only observed on $X$-, $Y$-directions, its bending directions. However, in both cases, the maximal anisotropy was 2 , which is lower than every silicon membrane based microprobes with low stiffnesses $\left(<0.4 \mathrm{~N} \cdot \mathrm{mm}^{-1}\right)$ and could be re-adjusted to zero by slightly tuning the membrane thickness of SPs depending on their position in the microprobe. A very long stylus $(10 \mathrm{~mm})$ was chosen here to evaluate the system under extreme conditions. 
Table 4. Measured stiffness in $X-, Y$-, and $Z$-direction for a $3 D S P$ w/ and $w / o$ stylus.

\begin{tabular}{lcc}
\hline & w/ stylus & w/o stylus \\
\hline $\mathbf{S}_{\mathbf{X}}$ in $\mathbf{N} \cdot \mathbf{m m}^{-1}$ & 0.162 & 0.286 \\
\hline $\mathbf{S}_{\mathbf{Y}}$ in $\mathbf{N} \cdot \mathbf{m m}^{-1}$ & 0.166 & 0.288 \\
\hline $\mathbf{S}_{\mathbf{Z}}$ in $\mathbf{N} \cdot \mathbf{m m}^{-1}$ & 0.326 & 0.326 \\
\hline max. anisotropy & 2.01 & 1.14 \\
\hline
\end{tabular}

For the sensor characterization, the 3DSP was deflected over a range of $\pm 200 \mu \mathrm{m}$ on $X, Y$, and $+200 \mu \mathrm{m}$ on $Z$. For each deflection direction, the corresponding output signals are shown for a 3DSP without a stylus in Fig. 15c. Similar to the 3DSP with foil wiring (II.D.3), the new version of the 3DSP present a $d_{\text {lin }}<0.27 \%$. However, with the one-step assembly, cross talk could be reduced to less than $2 \%$ between all axes.

The measured sensitivities on each direction with and without a stylus are listed in Table 5. The measured standard deviations in $\mathrm{E}$ over three repetitions was less than $0.3 \%$, proving an excellent repeatability of the sensors of the 3DSP. With the stylus, a maximum anisotropy of 2.53 is observed on $\mathrm{E}$, which does not pose any problem in CMM measurements, as it can be compensated during calibration. In all directions, enough sensitivity for submicrometer resolution can be achieved. The recorded noise with the actual setup was $0.06 \mathrm{mV} \cdot \mathrm{V}^{-1}$, which corresponds to a resolution between $200 \mathrm{~nm}$ and $500 \mathrm{~nm}$ with the given sensitivities. In order to be competitive to other microprobes designs, a resolution of at least $10 \mathrm{~nm}$ has to reached in future work (by signal noise reduction and increase of sensitivity with adjustment of SP dimensions).

Table 5. Measured sensitivities in $X$-, $Y$-, and $Z$-direction for a $3 D S P$ w/ and w/o stylus.

\begin{tabular}{lcc}
\hline & w/ stylus & w/o stylus \\
\hline $\mathbf{E}_{\mathbf{X}}$ in $\mathbf{~} \mathbf{V} \cdot \mathbf{V} \cdot \boldsymbol{\mu m}^{-1}$ & 0.118 & 0.208 \\
\hline $\mathbf{E}_{\mathbf{Y}}$ in $\mathbf{~} \mathbf{V} \cdot \mathbf{V} \cdot \boldsymbol{\mu m}^{-1}$ & 0.141 & 0.235 \\
\hline $\mathbf{E}_{\mathbf{Z}}$ in $\mathbf{~} \mathbf{V} \cdot \mathbf{V} \cdot \boldsymbol{\mu m}^{-1}$ & 0.299 & 0.292 \\
\hline max. anisotropy & 2.53 & 1.40 \\
\hline
\end{tabular}

4) Towards industrial application

In ongoing research in collaboration with the PTB, the integration of the microprobe in a conventional CMM is investigated with the patended new design [55] in an approach, which is similar to the one reported earlier with other probe designs $[23,56]$. In comparison with some microprobes from the literature (see I), the developed 3DSP proposes a large measuring range with an isotropic mechanical behavior and small stiffness for a small size $(\varnothing 11 \mathrm{~mm})$, which suits industrial use (Fig. 16). In contrast to metals or polymers, monocrystalline silicon is a perfect non-degrading material [42]. Therefore, degradation of the SPs will not be a problem. However, the 3DSP may be subject to degradation, because of the interposers (made out of FR4) and the epoxy glue used for the assembly. In the future, fatigue studies over longer durations will be carried out. The environmental temperature range in an industrial application is typically not exceeding $10-40{ }^{\circ} \mathrm{C}$ and is even much narrower in our measurement facilities $\left(22.5 \pm 3^{\circ} \mathrm{C}\right)$. As mentioned in the works [43-45] the Young's modulus E of the silicon changes with temperature with a slope of
$13.9 \cdot 10^{-3} \mathrm{GPa} \cdot \mathrm{K}^{-1}$ [45] for a (100) crystal orientation. The influence even for an industrial environment is lower than $0.3 \%$, which seems negligible. However, the assembled 3DSPs should be characterized within a temperature range of $10-40^{\circ} \mathrm{C}$ in the future because of potential influences from the assembly with FR4 interposers.

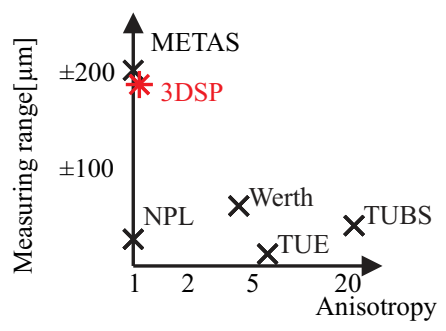

Fig. 16. Comparison of achieved measuring ranges and anisotropies for the new 3DSP with some microprobes described in the literature.

\section{SUMMARY AND OUTLOOK}

A unique new tactile microprobe with an isotropic parallelogram kinematic construction is presented. It is based on advanced miniaturization of double bending beam load cells made from monocrystalline silicon, which promises a mechanically perfect design and important advantages for the use in conventional CMMs and other 3D measurements. Simulations and measurements with first prototypes confirmed the isotropic behavior with low stiffness $\left(0.3 \mathrm{~N} \cdot \mathrm{mm}^{-1}\right)$. A parametric study reveals that it is possible to adjust the geometrical parameters of the SP for improved stability. The developed wafer-level fabrication process of the SPs enables a high integration density, a high manufacturing accuracy, and highly reproducible fabrication at low costs. The doping of silicon provides high sensitivities at high integration density. A very compact microprobe contained in a $\emptyset 11 \mathrm{~mm}$ housing could be realized. Further, a new assembly and wiring concept by interposers made from FR4 as mechanical and electrical interfaces is demonstrated. With the excellent mechanical properties of monocrystalline silicon perfect linear response was confirmed not only for the mechanical deflection, but also for the electrical signals over a wide deflection range $( \pm 200 \mu \mathrm{m})$. With the compact and robust integration concept, the microprobe seems to be very appropriate for industrial use. Future works will concentrate on improving the resolution (noise suppression and sensitivity optimization), on long-term stability and repeatability studies, and on further reduction of fabrication tolerances.

\section{ACKNOWLEDGEMENTS}

We thank M. David, B. Zhou, E. Charfi, K. Jiang, J. Chaillot and J. Garcia for assistance during the development, fabrication and measurements.

This research was supported by the Deutsche Forschungsgemeinschaft, DFG, project number DI 1934/5-1. 


\section{REFERENCES}

[1] Metz, D., Dietzel, A., "New parallelogram 3Ddisplacement sensor for micro probing and dimensional metrology", Transducers'17, Kaohsiung, The 19th International Conference on Solid-State Sensors, Actuators and Microsystems : June 18-22, 2017, Kaohsiung, Taiwan, Kaohsiung, pp. 982-985, 2017. DOI 10.1109/TRANSDUCERS.2017.7994215.

[2] "How Does a Bending Beam Load Cell Work? | Working Principle", HBM,

URL: https://www.hbm.com/en/2973/how-does-abending-beam-load-cell-work/. Accessed on 09.09.2018.

[3] “LSM250 Parallelogram Load Cell”, Futek, URL: http://www.futek.com/product.aspx?stock=FSH039 23. Accessed on 09.09.2018.

[4] VPG Transducers - Vishay Precision Group (VPG), "Load Cell Technology - Technical Note",

[5] Weckenmann, A., Estler, T., Peggs, G., McMurtry, D., "Probing systems in dimensional metrology", CIRP Annals - Manufacturing Technology, vol. 53, no. 2, pp. 657-684, 2004. DOI 10.1016/S0007-8506(07)60034-1.

[6] Weckenmann, A., Peggs, G. N., Hoffmann, J., "Probing systems for dimensional micro- and nano-metrology", Measurement Science and Technology, vol. 17, no. 3, pp. 504-509, 2006. DOI 10.1088/0957-0233/17/3/S08.

[7] Schwenke, H., Wäldele, F., Weiskirch, C., Kunzmann, H., "Opto-tactile sensor for 2D and 3D measurement of small structures on coordinate measuring Machines", CIRP Annals - Manufacturing Technology, vol. 50, no. 1, pp. 361-364, 2001. DOI 10.1016/S0007-8506(07)62140-4.

[8] Linz, S., Schoch, A., Bach, C., Ettemeyer, A., Hopp, B., Andras, M., "3D fiber probe, State of the art and new developments", International Symposium on Optomechatronic Technologies (ISOT), 2012, 29 - 31 Oct. 2012, Paris, France, Paris, France, pp. 1-4, 2012. DOI 10.1109/ISOT.2012.6403236.

[9] "Werth Fiber Probe WFP 3D - High Precision 3D Measurement - Werth Messtechnik",

URL: https://www.werth.de/en/unserangebot/products/sensors/werth-3d-fiber-probe-wfp.html. Accessed on 09.09.2018.

[10]Neuschaefer-Rube, U.; Bremer, H.; Hopp, B.; Christoph, R., "Recent developments of the 3D fiber probe", 11th Laser Metrology for Precision Measurement and Inspection in Industry (2014), Tsukuba, Japan.

[11]Peggs, G. N., Lewis, A. J., Oldfield, S., "Design for a compact high-accuracy CMM", CIRP Annals Manufacturing Technology, vol. 48, no. 1, pp. 417-420, 1999. DOI 10.1016/S0007-8506(07)63216-8.

[12]Lewis, A. J., "Fully traceable miniature CMM with submicrometer uncertainty", Optics \& Photonics, Proc. SPIE 5190, Recent Developments in Traceable Dimensional Measurements II, San Diego, California, USA, pp. 265-276, 2003. DOI 10.1117/12.503349.

[13]Leach, R. K., Haycocks, J., Jackson, K., Lewis, A. J., Oldfield, S., Yacoot, A., "Advances in traceable nanometrology at the National Physical Laboratory", INSTITUTE OF PHYSICS PUBLISHING, 2001. DOI 10.1088/0957-4484/12/1/201.
[14]Peggs, G. N., Lewis, A. J., Leach, R. K., "Measuring the metrology gap - three dimensional metrology at the mesoscopic level", Journal of Manufacturing Processes, vol. 6, no. 1, pp. 117-124, 2004. DOI 10.1016/S15266125(04)70065-1.

[15]Bos, E. J.C., "Tactile 3D probing system for measuring MEMS with nanometer uncertainty:aspects of probing, design, manufacturing and assembly", Technische Universiteit Eindhoven, 2008. ISBN 978-90-386-1216-4.

[16]Bos, E.J.C., Heldens, R.W.P., Delbressine, F.L.M., Schellekens, P.H.J., Dietzel, A., "Compensation of the anisotropic behavior of single crystalline silicon in a 3D tactile sensor", Sensors and Actuators A: Physical, vol. 134, no. 2, pp. 374-381, 2007. DOI 10.1016/j.sna.2006.05.043.

[17]Bos, E.J.C., "Aspects of tactile probing on the micro scale", Precision Engineering, vol. 35, no. 2, pp. 228-240, 2011. DOI 10.1016/j.precisioneng.2010.09.010.

[18]Bütefisch, S., Büttgenbach, S., Kleine-Besten, T., Brand, U., "Micromechanical three-axial tactile force sensor for micromaterial characterisation", Microsystem Technologies, vol. 7, no. 4, pp. 171-174, 2001. DOI $10.1007 / \mathrm{s} 005420000083$.

[19]Bütefisch, S., Solzbacher, F., Ziermann, R., Krause, P., Büttgenbach, S., Wilke, R., Cao, S., Pornnoppadol, P., Brand U., Seitz, K., Roth, R., "Mikrotaster für Anwendungen in der taktilen Wegmesstechnik (Micro Probe for Dimensional Metrology)", Technisches Messen, no. 70, 2003. DOI 10.1524/teme.70.5.238.20049.

[20]Phataralaoha, A., "Entwicklung piezoresistiver taktiler Sensoren für die Charakterisierung von Mikrokomponenten", Shaker, Aachen, 2009. ISBN 3832284443.

[21]Tibrewala, A., Phataralaoha, A., Büttgenbach, S., "Analysis of full and cross-shaped boss membranes with piezoresistors in transversal strain configuration", Journal of Micromechanics and Microengineering, vol. 18, no. 5, p. 55001, 2008. DOI 10.1088/0960-1317/18/5/055001.

[22]Ferreira, N., Brennecke, A., Dietzel, A., Buttgenbach, S., Krah, T., Metz, D., Kniel, K., Hartig, F., "Reducing the probe ball diameters of 3D silicon-based microprobes for dimensional metrology", 2013 Seventh International Conference on Sensing Technology (ICST), Wellington, New Zealand, pp. 301-306, 2013. DOI 10.1109/ICSensT.2013.6727663.

[23]Ferreira, N., Krah, T., Jeong, D. C., Metz, D., Kniel, K., Dietzel, A., Büttgenbach, S., Härtig, F., "Integration of a silicon-based microprobe into a gear measuring instrument for accurate measurement of micro gears", Measurement Science and Technology, vol. 25, no. 6, p. 64016, 2014. DOI 10.1088/0957-0233/25/6/064016.

[24]Ferreira, N., Metz, D., Dietzel, A., Buttgenbach, S., Krah, T., Kniel, K., Hartig, F., "3D micro probing systems for gear measurements with nanometer-scale deviation”, 2013 International Conference on Manipulation, Manufacturing and Measurement on the Nanoscale (3M-NANO), 26 - 30 Aug. 2013, Suzhou, China, Suzhou, China, pp. 253-258, 2013. DOI 10.1109/3M-NANO.2013.6737426.

[25]Buetefisch, S., Dai, G., Danzebrink, H.-U., Koenders, L., Solzbacher, F., Orthner, M. P., "Novel design for an ultra 
high precision 3D micro probe for CMM applications", Procedia Engineering, vol. 5, pp. 705-712, 2010. DOI 10.1016/j.proeng.2010.09.207.

[26]Metz, D., Ferreira, N., Dietzel, A., “3D piezoresistive silicon microprobes with stacked suspensions for tailored mechanical anisotropies", Sensors and Actuators A: Physical, vol. 267, pp. 164-176, 2017. DOI 10.1016/j.sna.2017.09.039.

[27]Masuzawa, T., Hamasaki, Y., Fujino, M., "Vibroscanning Method for Nondestructive Measurement of Small Holes", CIRP Annals - Manufacturing Technology, vol. 42, no. 1, pp. 589-592, 1993. DOI 10.1016/S00078506(07)62516-5.

[28]Masuzawa, T., Kim, B. J., Bergaud, C., Fujino, M., "Twin-Probe Vibroscanning Method for Dimensional Measurement of Microholes", CIRP Annals, vol. 46, no. 1, pp. 437-440, 1997. DOI 10.1016/S00078506(07)60860-9.

[29]Goj, B., Dressler, L., Hoffmann, M., "Design and characterization of a resonant triaxial microprobe", Journal of Micromechanics and Microengineering, vol. 25 , no. 12 , p. 125011,2015 . DOI 10.1088/0960$1317 / 25 / 12 / 125011$.

[30]Claverley, J. D., Leach, R. K., "Development of a threedimensional vibrating tactile probe for miniature CMMs", Precision Engineering, vol. 37, no. 2, pp. 491-499, 2013. DOI 10.1016/j.precisioneng.2012.12.008.

[31]“MITUTOYO, UMAP Vision System", URL: http://www.mitutoyo.co.jp/eng/.

[32]Küng, A., Meli, F., Thalmann, R., "Ultraprecision microCMM using a low force 3D touch probe", Measurement Science and Technology, vol. 18, no. 2, pp. 319-327, 2007. DOI 10.1088/0957-0233/18/2/S01.

[33]Thalmann, R., Meli, F., Küng, A., "State of the Art of Tactile Micro Coordinate Metrology", Applied Sciences, vol. 6, no. 5, p. 150, 2016. DOI 10.3390/app6050150.

[34]"Metallic materials - Calibration of force-proving instruments used for the verification of uniaxial testing machines" (2011), no. EN ISO 376.

[35]Aydemir, B., Kaluc, E., Fank, S., "Influence of heat treatment on hysteresis error of force transducers manufactured from 17-4PH stainless steel", Measurement, vol. 39 , no. 10 , pp. 892-900, 2006. DOI 10.1016/j.measurement.2006.03.014.

[36]Aydemir, B., Yagmur, L., Fank, S., "Hysteresis errors of commonly used sensor materials", Measurement, vol. 43, no. 6, pp. 792-796, 2010. DOI 10.1016/j.measurement.2010.02.013.

[37]OIML R60:2013, "Metrological Regulation for Load Cells" (2013).

[38]Kühnel, M., Hilbrunner, F., Büchner, H., Jäger, G., Manske, E., Fröhlich, T., "Traceable measurement of mechanical parameters of double bending beam force transducers according to EN ISO 376", Measurement, vol. 51, pp. 336-342, 2014. DOI 10.1016/j.measurement.2014.02.024.

[39]Mohamed, M. I., Hasan, E. H., Aggag, G., "Study of creep behavior of load cells", Measurement, vol. 42, no. 7, pp. 1006-1010, 2009. DOI 10.1016/j.measurement.2009.03.001.
[40]Tilli, M., Haapalinna, A., "Properties of Silicon" in: Tilli, M.; Motooka, T.; Airaksinen, V.-M.; Franssila, S.; Paulasto-Kröckel, M.; Lindroos, V. (editors), "Handbook of silicon based MEMS materials and technologies", Amsterdam, Boston, Heidelberg, London, 2015. ISBN 9780323299657.

[41]"Handbook of silicon based MEMS materials and technologies", Tilli, M.; Motooka, T.; Airaksinen, V.-M.; Franssila, S.; Paulasto-Kröckel, M.; Lindroos, V. (editors), Amsterdam, Boston, Heidelberg, London, 2015 ISBN 9780323299657.

[42]Muhlstein, C. L., Brown, S. B., Ritchie, R. O., "Highcycle fatigue of single-crystal silicon thin films", Journal of Microelectromechanical Systems, vol. 10, no. 4, pp. 593-600, 2001. DOI 10.1109/84.967383.

[43]Cho, C.-H., "Characterization of Young's modulus of silicon versus temperature using a "beam deflection" method with a four-point bending fixture", Current Applied Physics, vol. 9, no. 2, pp. 538-545, 2009. DOI 10.1016/j.cap.2008.03.024.

[44]Shirai, K., "Temperature Dependence of Young's Modulus of Silicon", Japanese Journal of Applied Physics, vol. 52, no. 8R, p. 88002, 2013. DOI 10.7567/JJAP.52.088002.

[45]Vanhellemont, J., Swarnakar, A. K., van der Biest, O., "Temperature Dependent Young's Modulus of Si and Ge", ECS Transactions, vol. 64, no. 11, pp. 283-292, 2014. DOI 10.1149/06411.0283ecst.

[46]Gere, J. M., "Mechanics of Materials", 6. ed., Brooks/Cole-Thomson Learning Inc., 2004. ISBN 0-53441793-0.

[47]Hopcroft, M. A., Nix, W. D., Kenny, T. W., "What is the Young's Modulus of Silicon?", Journal of Microelectromechanical Systems, vol. 19, no. 2, pp. 229238, 2010. DOI 10.1109/JMEMS.2009.2039697.

[48]“M-5x1.5i”, Yumpu, URL: https://www.yumpu.com/en/document/view/253386 96/micropositioners-hexapod-systems-pi-physikinstrumente/45. Accessed on 13.07.2017.

[49]"PI - Solution for precision motion and positioning", Physik Instrumente (PI) GmbH,

URL: https://www.physikinstrumente.com/. Accessed on 13.07.2017.

[50]"Characteristics of force transducers" (2008), no. VDI/VDE/DKD 2638.

[51]Ferreira, N., "Entwicklung, Integration und Erprobung eines piezoresistiven 3D-Mikrotasters, Dissertation", Shaker, Aachen, 2015. ISBN 9783844035469.

[52]Richter, C., Krah, T., Büttgenbach, S., "Novel 3D manufacturing method combining microelectrial discharge machining and electrochemical polishing", Microsystem Technologies, vol. 18, no. 7-8, pp. 1109-1118, 2012. DOI 10.1007/s00542-012-1452-x.

[53]Hale, L. C., Slocum, A. H., "Optimal design techniques for kinematic couplings", Precision Engineering, vol. 25, no. 2, pp. 114-127, 2001. DOI 10.1016/S01416359(00)00066-0.

[54]Furse, F. E., "Kinematic design of fine mechanisms in instruments", J. Phys. E: Sci. Instrum., vol. 14, 264-272, 1981. DOI 10.1088/0022-3735/14/3/001. 
[55]David Metz; Andreas Dietzel, "Mikrotaster und Verfahren zur Herstellung" (2017), no. DE 102017206145 B3.

[56]Metz, D., Ferreira, N., Chaillot, J., Stein, M., Kniel, K., Dietzel, A., "Integration of a piezoresistive microprobe into a commercial gear measuring instrument", Precision Engineering, 2018. DOI

10.1016/j.precisioneng.2018.10.003.

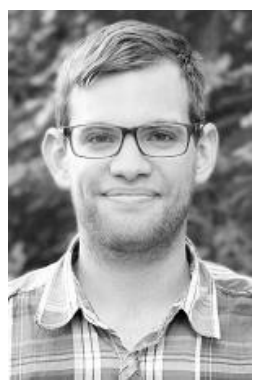

David Metz was born in Sélestat, France, in 1989. He received diploma degrees in mechanical engineering with a specialization in mechatronics, from the Technische Universität Braunschweig, Germany, and from the Université de Technologie de Compiègne, France, in 2013. Since 2013 he has been a research assistant and $\mathrm{PhD}$ student with the Institute of Microtechnology of

Technische Universität Braunschweig. His research interests are design and microfabrication of piezoresistive force sensors and their application in tactile metrology and coordinate measuring systems.

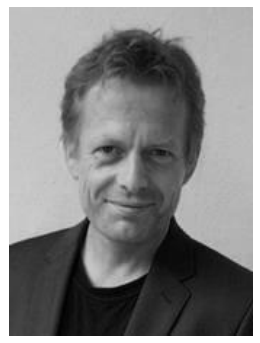

Andreas Dietzel studied physics at the University of Göttingen and received his $\mathrm{PhD}$ in 1989 at the Institute of Medical Physics and Biophysics.From 1990 to 2003 he worked for IBM research and development at laboratories of the Microelectronics Division in Böblingen (D), the Research Division in Rüschlikon $(\mathrm{CH})$ and the Storage Systems Division in Mainz (D) where from 1996 to 2003 he was heading a laboratory department. In 2003 he joined Robert Bosch Reutlingen (D) as project manager for "base development of acceleration sensors of the 3rd generation". In 2004 he joined the University of Technology in Eindhoven (NL) as a full professor for "Micro and Nanoscale Engineering". In the years 2007 to 2011, he was also program manager for the TNO Holst Centre System-in-Foil open innovation platform. In 2012, he was appointed full professor at the Technische Universität Braunschweig and has since been director of the Institute of Microtechnology. His research focuses on the design and fabrication of MEMS, systems-in-foil, and of microfluidic systems with applications in the life sciences. 